\title{
Leaf-scale experiments reveal an important omission in the Penman-Monteith equation
}

\author{
Stanislaus J. Schymanski and Dani Or \\ Department of Environmental Sciences, ETH Zurich, 8092 Zurich, Switzerland \\ Correspondence to: Stanislaus J. Schymanski (stan.schymanski@env.ethz.ch)
}

Received: 19 July 2016 - Published in Hydrol. Earth Syst. Sci. Discuss.: 26 July 2016

Revised: 5 December 2016 - Accepted: 7 January 2017 - Published: 2 February 2017

\begin{abstract}
The Penman-Monteith (PM) equation is commonly considered the most advanced physically based approach to computing transpiration rates from plants considering stomatal conductance and atmospheric drivers. It has been widely evaluated at the canopy scale, where aerodynamic and canopy resistance to water vapour are difficult to estimate directly, leading to various empirical corrections when scaling from leaf to canopy. Here, we evaluated the PM equation directly at the leaf scale, using a detailed leaf energy balance model and direct measurements in a controlled, insulated wind tunnel using artificial leaves with fixed and predefined stomatal conductance. Experimental results were consistent with a detailed leaf energy balance model; however, the results revealed systematic deviations from PM-predicted fluxes, which pointed to fundamental problems with the PM equation. Detailed analysis of the derivation by Monteith (1965) and subsequent amendments revealed two errors: one in neglecting two-sided exchange of sensible heat by a planar leaf, and the other related to the representation of hypostomatous leaves, which are very common in temperate climates. The omission of two-sided sensible heat flux led to bias in simulated latent heat flux by the PM equation, which was as high as $50 \%$ of the observed flux in some experiments. Furthermore, we found that the neglect of feedbacks between leaf temperature and radiative energy exchange can lead to additional bias in both latent and sensible heat fluxes. A corrected set of analytical solutions for leaf temperature as well as latent and sensible heat flux is presented, and comparison with the original PM equation indicates a major improvement in reproducing experimental results at the leaf scale. The errors in the original PM equation and its failure to reproduce experimental results at the leaf scale (for which it was originally derived) propagate into inaccurate sensitivi-
\end{abstract}

ties of transpiration and sensible heat fluxes to changes in atmospheric conditions, such as those associated with climate change (even with reasonable present-day performance after calibration). The new formulation presented here rectifies some of the shortcomings of the PM equation and could provide a more robust starting point for canopy representation and climate change studies.

\section{Introduction}

A vast number of current global land surface models, hydrological models and inverse approaches to deduce evaporation from remote sensing data employ the analytical solution for the latent heat flux from plant leaves derived by Monteith (1965), based on an earlier formulation for a wet surface by Penman (1948), see e.g. Overgaard et al. (2006) and Dolman et al. (2014). This so-called Penman-Monteith equation (henceforth referred to as the PM equation), which introduced stomatal resistance into Penman's formalism, found widespread use in the prediction of latent heat flux based on estimates of leaf and canopy resistance to water vapour. Whereas the PM equation is generally believed to provide an adequate physical description of transpiration from an individual leaf, it is commonly applied at the canopy scale, where aerodynamic and bulk stomatal resistance are difficult to estimate and are usually deduced empirically from measurements of transpiration and an inverted PM equation (Raupach and Finnigan, 1988) or from observed surface temperatures (Tanner and Fuchs, 1968). The scaling up from leaf to canopy is commonly done in an ad hoc manner by replacing the leaf-scale resistances with their assumed canopy-scale counterparts, often without any additional physics involved. The 
leaf-canopy scaling and use of data at daily or monthly scales has led to various empirical corrections to the PM equation (Allen, 1986), which may have obscured more fundamental issues with the derivations by Monteith (1965). On the other hand, Langensiepen et al. (2009) proposed a detailed leafscale parametrisation of the PM equation and averaging over the canopy and time that yielded reasonable agreement with sap-flow-derived canopy transpiration estimates, without empirical corrections to the PM equation.

A number of authors have focused on biases introduced by the simplifications inherent in the PM equation, such as the linearisation of the saturation vapour pressure curve and the neglect of dependency of net irradiance on surface temperature, and proposed various approaches to reduce such biases (Paw U and Gao, 1988; McArthur, 1990; Milly, 1991; Widmoser, 2009). Interestingly, even 50 years after its derivation, we have not found a rigorous test of the PM equation at the leaf scale, whereas our analysis of the derivations by Monteith (1965) and later amendments revealed two errors in considering the effect of stomata and the two-sided exchange of sensible heat. Therefore, the objectives of the present study are to

1. develop an experimental set-up allowing direct and independent measurement of all components of the energy balance of a single leaf and the relevant boundary conditions,

2. compare different analytical and numerical leaf energy balance and gas exchange models with experimental results and

3. derive an improved analytical representation of latent and sensible heat fluxes at the leaf scale.

The study is structured as follows. We first present a physically based, explicit leaf energy balance and gas exchange model, to serve as a reference for the physical processes. The explicit model is then used to rederive the Penman and Penman-Monteith (PM) equations while highlighting all simplifying assumptions inherent in these formulations. Subsequently, we will derive a general analytical formulation based on the approach by Penman (1952) and analyse consistency between the various analytical solutions and the explicit leaf energy and gas exchange model. In the next step, we will present an experimental set-up allowing us to measure all components of the leaf energy balance under fully controlled conditions, using artificial leaves with known stomatal conductance. Experimental results will be compared with the explicit numerical model and the different analytical solutions, assessing potential bias.

\section{Materials and methods}

The detailed derivations are described in the Appendix, while the experimental methods are discussed in detail in a technical note submitted to HESS (Schymanski et al., 2017). Here, we only summarise the key points and concepts necessary to understand the flow of the paper. All symbols used in this paper are listed and described in the Appendix, Table A1. Additionally, all derivations, data and code to reproduce the results are provided online and can be accessed at https://github.com/schymans/Schymanski_ leaf-scale_2016/tree/1.0.0 and doi:10.5281/zenodo.241259 (Schymanski, 2017). Data analysis was performed using the free software SageMath, the Sage Mathematics Software System (version 7.3), The Sage Developers, 2016 (http:// www.sagemath.org).

\subsection{Explicit leaf energy balance and gas exchange model}

The detailed leaf energy balance model used here is based on derivations published previously (Schymanski et al., 2013; Schymanski and Or, 2015, 2016), and is reproduced here after reorganisation of equations for consistency with the present paper.

The leaf energy balance is determined by the dominant energy fluxes between the leaf and its surroundings, including radiative, sensible and latent energy exchange (linked to mass exchange). These are illustrated in Fig. 1. Focusing on steady-state conditions, the energy balance can be written as

$R_{\mathrm{S}}=E_{1}+H_{1}+R_{11}$,

where $R_{\mathrm{S}}\left(\mathrm{W} \mathrm{m}^{-2}\right)$ is absorbed short-wave radiation, $E_{1}$ $\left(\mathrm{W} \mathrm{m}^{-2}\right)$ is the latent heat flux away from the leaf, $H_{1}$ $\left(\mathrm{W} \mathrm{m}^{-2}\right)$ is the sensible heat flux away from the leaf and $R_{l 1}\left(\mathrm{~W} \mathrm{~m}^{-2}\right)$ is the net emitted long-wave radiation, i.e. the emitted minus the absorbed radiation. In the above, extensive variables are defined per unit leaf area. Following our previous work (Schymanski et al., 2013), this study considers spatially homogeneous planar leaves, i.e. homogenous illumination and a negligible temperature gradient between the two sides of the leaf. The net long-wave emission is represented by the difference between blackbody radiation at leaf temperature $\left(T_{1}, \mathrm{~K}\right)$ and that at the temperature of the surrounding objects $\left(T_{\mathrm{w}}\right.$, commonly represented by air temperature, $T_{\mathrm{a}}$, both in K) (Monteith and Unsworth, 2007):

$R_{\mathrm{ll}}=a_{\mathrm{sH}} \epsilon_{1} \sigma\left(T_{1}^{4}-T_{\mathrm{w}}^{4}\right)$,

where $a_{\mathrm{sH}}$ is the fraction of projected leaf area exchanging radiative and sensible heat ( 2 for a planar leaf, 1 for a soil surface), $\epsilon_{1}$ is the leaf's long-wave emissivity $(\approx 1)$ and $\sigma$ $\left(\mathrm{W} \mathrm{K}^{-4} \mathrm{~m}^{-2}\right.$ ) is the Stefan-Boltzmann constant. Total convective heat transport away from the leaf is represented as

$H_{1}=a_{\mathrm{sH}} h_{\mathrm{c}}\left(T_{1}-T_{\mathrm{a}}\right)$,

where $h_{\mathrm{c}}\left(\mathrm{W} \mathrm{K}^{-1} \mathrm{~m}^{-2}\right)$ is the average one-sided convective heat transfer coefficient, determined by properties of the leaf boundary layer. 


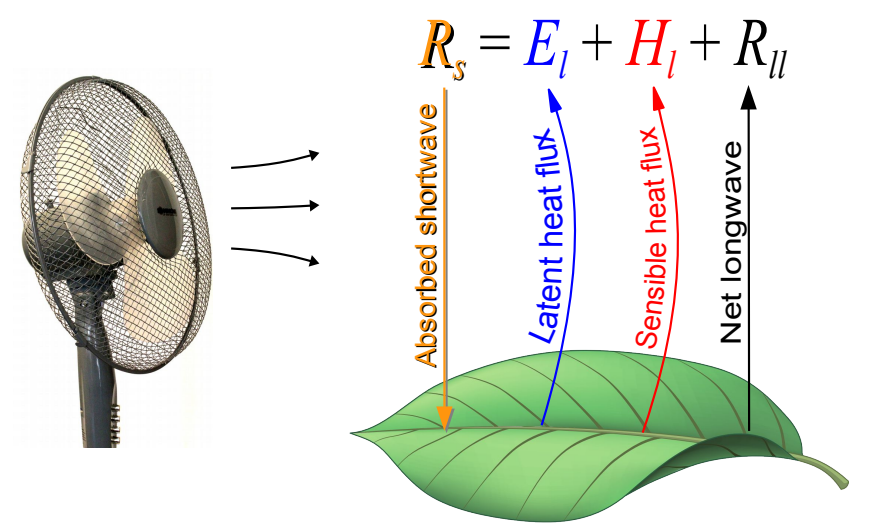

\begin{tabular}{|c|c|c|}
\multicolumn{1}{c|}{ Flux } & Equation & Driver \\
\hline Latent heat & $E_{l}=L M_{w} g_{t v}\left(C_{w l}-C_{w a}\right)$ & Vapour conc. \\
Sensible heat & $H_{l}=2 h_{c}\left(T_{l}-T_{a}\right)$ & Temperature \\
Longwave & $R_{l l}=2 \sigma\left(T_{l}^{4}-T_{a}^{4}\right)$ & Temperature \\
\hline \multicolumn{2}{c}{$\left(C_{w l}-C_{w a}\right)$} & $=f\left(R H, T_{l}, T_{a}\right)$ \\
$g_{t v}, h_{c} \sim \operatorname{sqrt}($ wind $)$ &
\end{tabular}

Figure 1. Components of the leaf energy balance and their thermodynamic drivers. Bent arrows indicate fluxes that are directly affected by wind speed. Table at bottom illustrates the drivers for each flux (temperature differences for sensible and radiative heat exchange, water vapour concentration differences for mass exchange and hence latent heat flux). Additional equations below the table illustrate that the driver for latent heat flux is also related to temperature differences and that the transfer coefficients for both latent and sensible heat flux depend on wind. $L$ : latent heat of vaporisation, $M_{\mathrm{W}}$ : molecular mass of water, $g_{\mathrm{tw}}$ : total leaf conductance to water vapour, $C_{\mathrm{wl}}$ : concentration of water vapour in leaf-internal air, $C_{\text {wa }}$ : concentration of water vapour in free air stream, $h_{\mathrm{c}}$ : one-sided heat transfer coefficient, $T_{1}$ : leaf temperature, $T_{\mathrm{a}}$ : air temperature, $\sigma$ : Stefan-Boltzmann constant, RH: relative humidity of the free air stream, $g_{\text {bw }}$ : leaf boundary layer conductance to water vapour.

Latent heat flux $\left(E_{1}, \mathrm{~W} \mathrm{~m}^{-2}\right)$ is directly related to the transpiration rate $\left(E_{1, \mathrm{~mol}}, \mathrm{~mol} \mathrm{~m}^{-2} \mathrm{~s}^{-1}\right)$ by

$E_{1}=E_{1, \mathrm{~mol}} M_{\mathrm{w}} \lambda_{E}$,

where $M_{\mathrm{w}}\left(\mathrm{kg} \mathrm{mol}^{-1}\right)$ is the molar mass of water and $\lambda_{E}$ $\left(\mathrm{J} \mathrm{kg}^{-1}\right)$ the latent heat of vaporisation. $E_{1, \mathrm{~mol}}\left(\mathrm{~mol} \mathrm{~m}^{-2} \mathrm{~s}^{-1}\right)$ was computed in molar units as a function of the concentration of water vapour within the leaf $\left(C_{\mathrm{wl}}, \mathrm{mol} \mathrm{m}^{-3}\right)$ and in the free air $\left(C_{\mathrm{wa}}, \mathrm{mol} \mathrm{m}^{-3}\right)$ (Incropera et al., 2006, Eq. 6.8):

$E_{1, \mathrm{~mol}}=g_{\mathrm{tw}}\left(C_{\mathrm{wl}}-C_{\mathrm{wa}}\right)$,

where $g_{\mathrm{tw}}\left(\mathrm{m} \mathrm{s}^{-1}\right)$ is the total leaf conductance for water vapour, dependent on stomatal $\left(g_{\mathrm{sw}}\right)$ and the boundary layer conductance $\left(g_{\mathrm{bw}}\right)$ in the following way:

$g_{\mathrm{tw}}=\frac{1}{\frac{1}{g_{\mathrm{sw}}}+\frac{1}{g_{\mathrm{bw}}}}$.
Both the one-sided leaf convective heat transfer coefficient $\left(h_{\mathrm{c}}\right)$ and boundary layer conductance to water vapour $\left(g_{\mathrm{bw}}\right.$, $\mathrm{m} \mathrm{s}^{-1}$ ) relate to the same physical principles of diffusion and boundary layer dynamics; i.e. both depend on leaf size $\left(L_{1}\right.$, $\mathrm{m})$, wind speed $\left(v_{\mathrm{w}}, \mathrm{m} \mathrm{s}^{-1}\right)$ and the level of turbulence in the air stream (critical Reynolds number, $N_{R e_{c}}$ ), expressed in the dimensionless Nusselt and Lewis numbers $\left(N_{N u_{L}}\right.$ and $N_{L e}$, respectively). The relation of $h_{\mathrm{c}}$ to $g_{\mathrm{bw}}$ additionally depends on whether stomata are present on one side of the leaf only $\left(a_{\mathrm{s}}=1\right)$ or both sides of the leaf $\left(a_{\mathrm{s}}=2\right)$. The relevant equations to compute all of these variables as a function of air temperature, pressure and vapour pressure $\left(T_{\mathrm{a}}, P_{\mathrm{a}}\right.$ and $P_{\mathrm{wa}}$, respectively), wind speed $\left(v_{\mathrm{W}}\right)$, turbulence and leaf properties are given in the Appendix, Sects. B1-B4.

Figure 2 illustrates the use of measurements and the different equations to compute the leaf energy balance components. Leaf temperature $\left(T_{1}\right)$ needs to be computed by iteration, using the leaf energy balance model, due to the nonlinearities in Eqs. (2) and (B5). Note that a direct measurement of $T_{1}$ (e.g. using infrared sensors) would enable direct computation of $R_{11}$ and $H_{1}$, and finally $E_{1}$ from the energy balance as $E_{1}=R_{\mathrm{S}}-R_{11}-H_{1}$ without any iterations. This illustrates that the use of any of the analytical solutions explained below is not necessary if $T_{1}$ is known and questions the approach proposed by Tanner and Fuchs (1968), where observed leaf or surface temperature is inserted into the Penman-Monteith equation to estimate transpiration rate.

\subsection{Generalisation of Penman's analytical approach}

The PM equation derived by Monteith (1965) was based on the analytical solution for evaporation from a wet surface by Penman (1948). The key point of Penman's analytical solution is to express evaporation as a function of the surface-air vapour pressure difference and sensible heat flux as a function of surface-air temperature difference. Here, we will follow the succinct derivation presented in the Appendix of Penman (1952) and use our notation for a leaf to obtain a general solution applicable either to a transpiring leaf or an evaporating surface. In the first step, we will introduce general transfer coefficients for latent heat $\left(c_{E}, \mathrm{~W} \mathrm{~m}^{-2} \mathrm{~Pa}^{-1}\right)$ and sensible heat $\left(c_{H}, \mathrm{~W} \mathrm{~m}^{-2} \mathrm{~K}^{-1}\right)$, satisfying the following equations:

$E_{1}=c_{E}\left(P_{\mathrm{wl}}-P_{\mathrm{wa}}\right)$

and

$H_{1}=c_{H}\left(T_{1}-T_{\mathrm{a}}\right)$.

(Please refer to Appendix B3 for a discussion of the meaning of Eq. 7 compared to Eq. 5, and conversion of transfer coefficients.)

Equations (7), (8) and the leaf energy balance equation (Eq. 1) form a system of three equations with four unknowns: $E_{1}, H_{1}, T_{1}$ and $P_{\mathrm{wl}}$. In order to eliminate $T_{1}$, Penman assumed that the ratio of the vapour pressure difference between the 


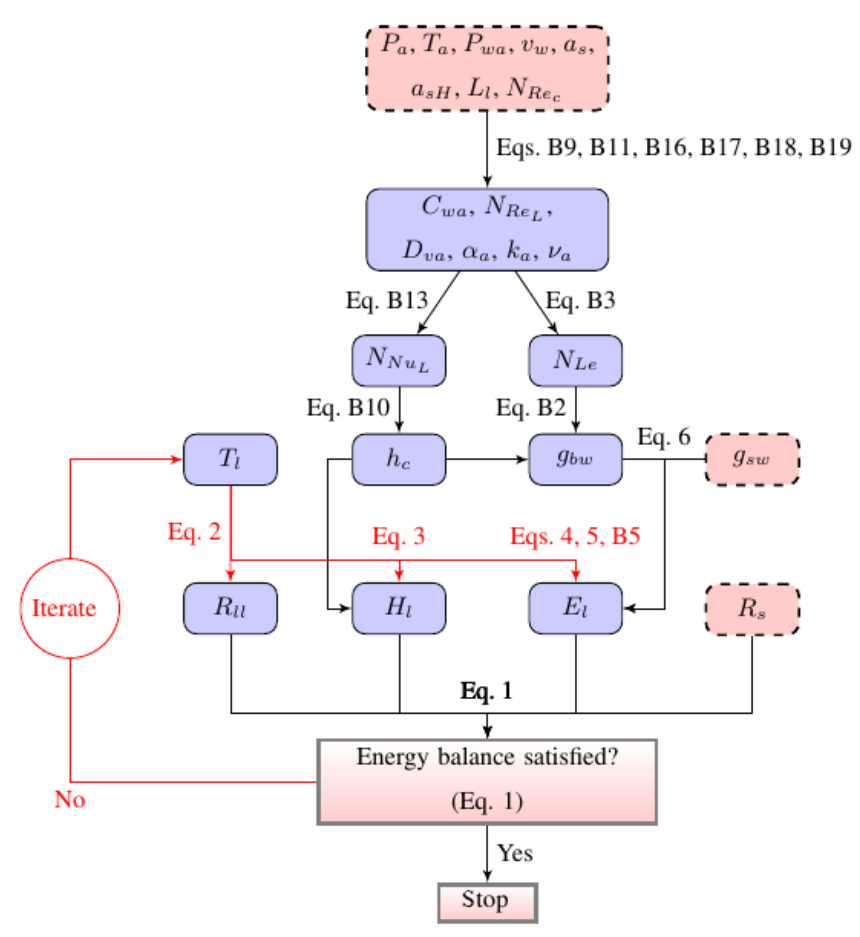

Figure 2. Flow chart of computation procedure for different leaf energy balance components. Dashed pink boxes with rounded corners indicate external input, while solid blue rounded boxes indicate computed variables. Note the central role of leaf temperature, which needs to be computed by iteration against the leaf energy balance.

surface and the saturation vapour pressure at air temperature $\left(P_{\text {was }}\right)$ to the temperature difference between the surface and the air can be approximated by the slope of the saturation vapour pressure curve at air temperature $\left(\Delta_{\mathrm{eTa}}, \mathrm{PaK}^{-1}\right)$ :

$\Delta_{\mathrm{eTa}}=\frac{P_{\mathrm{wl}}-P_{\mathrm{was}}}{T_{1}-T_{\mathrm{a}}}$.

This gives four equations (Eqs. 1, 7, 8 and 9) that can be solved for the four unknowns $E_{1}, H_{1}, T_{1}$ and $P_{\mathrm{wl}}$ :

$$
\begin{aligned}
& E_{1}=\frac{\Delta_{\mathrm{eTa}} c_{E}\left(R_{\mathrm{s}}-R_{11}\right)+c_{E} c_{H}\left(P_{\mathrm{was}}-P_{\mathrm{wa}}\right)}{\Delta_{\mathrm{eTa}} c_{E}+c_{H}}, \\
& H_{1}=\frac{c_{H}\left(R_{\mathrm{s}}-R_{11}\right)+c_{E} c_{H}\left(P_{\mathrm{wa}}-P_{\mathrm{was}}\right)}{\Delta_{\mathrm{eTa}} c_{E}+c_{H}}, \\
& T_{1}=T_{\mathrm{a}}+\frac{\left(R_{\mathrm{s}}-R_{11}\right)+c_{E}\left(P_{\mathrm{wa}}-P_{\mathrm{was}}\right)}{\Delta_{\mathrm{eTa}} c_{E}+c_{H}}
\end{aligned}
$$

and

$$
P_{\mathrm{wl}}=\frac{\Delta_{\mathrm{eTa}}\left(R_{\mathrm{S}}-R_{\mathrm{ll}}+P_{\mathrm{wa}} c_{E}\right)+P_{\mathrm{was}} c_{H}}{\Delta_{\mathrm{eTa}} c_{E}+c_{H}} .
$$

In the original formulations by Penman and Monteith, the term $R_{\mathrm{S}}-R_{\mathrm{ll}}$ is referred to as net available energy, and for a ground surface, it is represented by net radiation minus ground heat flux $\left(R_{\mathrm{N}}-G\right)$. For a leaf, there is no ground heat flux, and $R_{\mathrm{N}}=R_{\mathrm{S}}-R_{11}$. In most applications of the analytical solutions, $R_{\mathrm{ll}}$ is not explicitly calculated, but it is assumed that $R_{\mathrm{N}}$ is known, neglecting the dependence of $R_{11}$ on the leaf temperature. This neglect can be alleviated by linearising the equation for $R_{11}$ (Leuning et al., 1989), which was also done in Sect. 2.4, where we rederive Eqs. (10)-(12) based on a linearised equation for $R_{11}$, eliminating the need for separate estimation of $R_{\mathrm{N}}$.

To solve Eqs. (10)-(13), one only needs information about $c_{H}$ and $c_{E}$, appropriate for a leaf or an evaporating surface, whichever is the system of interest. For a planar leaf, $c_{H}=$ $a_{\mathrm{sH}} h_{\mathrm{c}}$ with $a_{\mathrm{sH}}=2$ as the leaf exchanges sensible heat on both sides, whereas for a soil surface, $a_{\mathrm{sH}}=1$. Comparison of Eqs. (4) and (7) with the common representation of $E_{1, \mathrm{~mol}}$ as a function of total leaf conductance to water vapour $\left(g_{\mathrm{tw}}\right)$ and water vapour mole fractions (Eq. B6) suggests that

$c_{E}=M_{\mathrm{w}} \lambda_{E} g_{\mathrm{tw}, \mathrm{mol}} / P_{\mathrm{a}}$,

where $g_{\mathrm{tw}, \mathrm{mol}}$ has an aerodynamic component related to $g_{\mathrm{bw}}$ (and hence $h_{\mathrm{c}}$ ) and a surface-specific component, related to $g_{\mathrm{sw}}$, as described in Appendix B1. Since planar leaves can have stomata on one or both sides, the relation between $h_{\mathrm{c}}$ and $g_{\mathrm{bw}}$ is not universal; i.e. $a_{\mathrm{s}}$ in Eq. (B2) can be equal to 1 or 2 , whereas for a soil surface $a_{\mathrm{s}}=1$.

\subsection{Inconsistencies in the PM equation}

From the general form (Eqs. 10-12), we can recover various analytical forms used for latent heat flux (e.g. Penman, 1948, 1952; Monteith, 1965), with the appropriate substitutions for $c_{E}$ and $c_{H}$. This is shown in detail in the Appendix, Sect. B8, where we also illustrate some inconsistencies in the published derivations. Here, we will discuss errors in the derivation of the PM equation, when it is intended for the simulation of leaf transpiration. The derivation is based on the Penman equation for a wet surface (Penman, 1948), which can be recovered from the above general solution by substituting $c_{E}=f_{\mathrm{u}}$ and $c_{H}=\gamma_{\mathrm{v}} f_{\mathrm{u}}$ into Eq. (10) (Fig. 3a):

$E_{\mathrm{w}}=\frac{\Delta_{\mathrm{eTa}}\left(R_{\mathrm{s}}-R_{\mathrm{ll}}\right)+f_{\mathrm{u}} \gamma_{\mathrm{v}}\left(P_{\mathrm{was}}-P_{\mathrm{wa}}\right)}{\Delta_{\mathrm{eTa}}+\gamma_{\mathrm{v}}}$,

where $f_{\mathrm{u}}\left(\mathrm{W} \mathrm{Pa}^{-1} \mathrm{~m}^{-2}\right)$ is often referred to as the "wind function".

Monteith (1965) rederived the Penman equation for wet surface evaporation (Eq. 15) using a different set of arguments and arrived at an equivalent equation (Eq. 8 in Monteith, 1965):

$$
E_{\mathrm{w}}=\frac{\Delta_{\mathrm{eTa}}\left(R_{\mathrm{s}}-R_{11}\right)+\rho_{\mathrm{a}} c_{\mathrm{pa}}\left(P_{\mathrm{was}}-P_{\mathrm{wa}}\right) / r_{\mathrm{a}}}{\Delta_{\mathrm{eTa}}+\gamma_{\mathrm{v}}},
$$

where $r_{\mathrm{a}}\left(\mathrm{s} \mathrm{m}^{-1}\right)$ is the leaf boundary layer resistance to sensible heat flux. Equation (16) is consistent with Eq. (15) if Penman's wind function $\left(f_{\mathrm{u}}\right)$ is replaced by

$f_{\mathrm{u}}=\frac{\rho_{\mathrm{a}} c_{\mathrm{pa}}}{\gamma_{\mathrm{v}} r_{\mathrm{a}}}$. 
Monteith pointed out that the ratio between the conductance to sensible heat and the conductance to water vapour transfer, expressed in the psychrometric constant $\left(\gamma_{\mathrm{v}}\right.$, $\mathrm{Pa} \mathrm{K}^{-1}$ ) would be affected by stomatal resistance $\left(r_{\mathrm{s}}, \mathrm{s} \mathrm{m}^{-1}\right)$ and hence proposed to replace the psychrometric constant by $\gamma_{\mathrm{v}}^{*}$ :

$\gamma_{\mathrm{v}}^{*}=\gamma_{\mathrm{v}}\left(1+\frac{r_{\mathrm{s}}}{r_{\mathrm{a}}}\right)$,

leading to the so-called Penman-Monteith equation for transpiration:

$E_{1}=\frac{\Delta_{\mathrm{eTa}}\left(R_{\mathrm{s}}-R_{11}\right)+\rho_{\mathrm{a}} c_{\mathrm{pa}}\left(P_{\mathrm{was}}-P_{\mathrm{wa}}\right) / r_{\mathrm{a}}}{\Delta_{\mathrm{eTa}}+\gamma_{\mathrm{v}}\left(1+\frac{r_{\mathrm{s}}}{r_{\mathrm{a}}}\right)}$.

To test whether Eq. (19) is physically consistent for a planar leaf, we deduce it from our more general Eq. (10), using suitable definitions for $c_{E}, c_{H}, r_{\mathrm{a}}$ and $r_{\mathrm{s}}$. Equation (19), with $\gamma_{\mathrm{v}}$ defined in Eq. (B46), could be recovered by substituting $c_{E}=\epsilon \lambda_{E} \rho_{\mathrm{a}} /\left(P_{\mathrm{a}}\left(r_{\mathrm{s}}+r_{\mathrm{v}}\right)\right)$ and $c_{H}=c_{\mathrm{pa}} \rho_{\mathrm{a}} / r_{\mathrm{a}}$ into Eq. (10), with subsequent substitution of $r_{\mathrm{v}}=r_{\mathrm{a}}$ (implicit in Eq. 17, considering that $f_{\mathrm{u}}=c_{E}$ ). Note, however, that $r_{\mathrm{a}}$ in Monteith's derivation is defined as one-sided resistance to sensible heat exchange (Monteith and Unsworth, 2013, p. 231), neglecting the fact that planar leaves exchange sensible heat on both sides. We suppose that this omission is related to the original Penman derivation, developed for a soil surface, which exchanges latent and sensible heat across one interface, and hence is not appropriate for a leaf. To alleviate this constraint, one could define $r_{\mathrm{a}}$ and $r_{\mathrm{s}}$ as total (two-sided) leaf resistances, but in this case, the simplification $r_{\mathrm{v}} \approx r_{\mathrm{a}}$ is not valid for hypostomatous leaves, as $r_{\mathrm{v}}$ would then be twice the value of $r_{\mathrm{a}}$. This is illustrated in Fig. 3c, where sensible heat flux is released from both sides of the leaf, while latent heat flux is only released from the abaxial side, implying that $a_{\mathrm{sh}}=2$ and $a_{\mathrm{s}}=1$.

Monteith and Unsworth (2013) acknowledged that a hypostomatous leaf could exchange sensible heat on two sides, but latent heat on one side only, and proposed to represent this fact by further modifying $\gamma_{\mathrm{v}}^{*}$ to

$\gamma_{\mathrm{v}}^{*}=n_{\mathrm{MU}} \gamma_{\mathrm{v}}\left(1+r_{\mathrm{s}} / r_{\mathrm{a}}\right)$,

where $n_{\mathrm{MU}}=1$ for leaves with stomata on both sides and $n_{\mathrm{MU}}=2$ for leaves with stomata on one side, i.e. $n_{\mathrm{MU}}=$ $a_{\mathrm{sh}} / a_{\mathrm{s}}$ in our notation. Insertion of Eq. (20) into Eq. (16) yields what we will call the Monteith-Unsworth (MU) equation, which only differs from the Penman-Monteith equation by the additional factor $n_{\mathrm{MU}}$ :

$E_{1}=\frac{\Delta_{\mathrm{eTa}}\left(R_{\mathrm{s}}-R_{\mathrm{ll}}\right)+\rho_{\mathrm{a}} c_{\mathrm{pa}}\left(P_{\mathrm{was}}-P_{\mathrm{wa}}\right) / r_{\mathrm{a}}}{\Delta_{\mathrm{eTa}}+\gamma_{\mathrm{v}} n_{\mathrm{MU}}\left(1+\frac{r_{\mathrm{s}}}{r_{\mathrm{a}}}\right)}$.

However, this was done by specifying $r_{\mathrm{s}}$ and $r_{\mathrm{a}}$ as onesided resistances when inserting them into the term for $\gamma_{\mathrm{v}}$ in Eq. (16), which was already based on the approximation $r_{\mathrm{v}} \approx r_{\mathrm{a}}$, which is not valid for hypostomatous leaves, as explained above. If we replace $r_{\mathrm{a}}$ by $r_{\mathrm{a}}=r_{\mathrm{a}} / a_{\mathrm{sh}}$ in Eq. (16) before substitution of Eq. (20), we obtain a corrected MU equation:

$E_{1}=\frac{\Delta_{\mathrm{eTa}}\left(R_{\mathrm{s}}-R_{\mathrm{ll}}\right)+\rho_{\mathrm{a}} c_{\mathrm{pa}}\left(P_{\mathrm{was}}-P_{\mathrm{wa}}\right) a_{\mathrm{sh}} / r_{\mathrm{a}}}{\Delta_{\mathrm{eTa}}+\gamma_{\mathrm{v}} a_{\mathrm{sh}} / a_{\mathrm{s}}\left(1+\frac{r_{\mathrm{s}}}{r_{\mathrm{a}}}\right)}$,

which only differs from Eq. (21) by the factor $a_{\mathrm{sh}}(=2)$ in the nominator. Equations (19) and (22) are only equivalent to each other if $a_{\mathrm{sh}}=1=a_{\mathrm{s}}$, implying that Eq. (19) is not applicable for any planar leaves. For symmetrical amphistomatous leaves, $a_{\mathrm{sh}}=2=a_{\mathrm{s}}$, in which case the classic PM equation is only missing a factor of 2 in the nominator, as pointed out by Jarvis and McNaughton (1986, Eq. A9).

\subsection{Analytical solution including radiative feedback}

The above analytical solutions eliminated the non-linearity problem of the saturation vapour pressure curve, but they do not consider the dependency of the long-wave component of the leaf energy balance $\left(R_{11}\right)$ on leaf temperature $\left(T_{1}\right)$, as expressed in Eq. (2). Therefore, the above analytical equations are commonly used in conjunction with fixed value of $R_{11}$, either taken from observations or the assumption that $R_{11}=0$. Here, we replace the non-linear Eq. (2) by its tangent at $T_{1}=T_{\mathrm{a}}$, which is given by

$R_{\mathrm{ll}}=4 a_{\mathrm{sh}} \epsilon_{1} \sigma T_{\mathrm{a}}^{3} T_{1}-a_{\mathrm{sh}} \epsilon_{1} \sigma\left(T_{\mathrm{w}}^{4}+3 T_{\mathrm{a}}^{4}\right)$.

Note that the common approximation of $T_{\mathrm{W}}=T_{\mathrm{a}}$ simplifies the above equation to $R_{11}=4 a_{\mathrm{sh}} \epsilon_{1} \sigma\left(T_{\mathrm{a}}^{3} T_{1}-T_{\mathrm{a}}^{4}\right)$. The linearisation introduces a bias of less than $-20 \mathrm{~W} \mathrm{~m}^{-2}$ in the calculation of $R_{11}$ for leaf temperatures $\pm 20 \mathrm{~K}$ of air temperature, compared to Eq. (2) (see Fig. A3).

We can now use a similar procedure as in Sect. 2.2, but this time it is aimed at eliminating $P_{\mathrm{wl}}$ using the Penman assumption, rather than eliminating $T_{1}$. We first eliminate $c_{E}$ from Eq. (7) by introducing the psychrometric constant as

$\gamma_{\mathrm{v}}=c_{H} / c_{E}$,

and introduce it into Eq. (8) to obtain

$H_{1}=\gamma_{\mathrm{v}} c_{E}\left(T_{1}-T_{\mathrm{a}}\right)$

Then, we insert the Penman assumption (Eq. 9) to eliminate $P_{\mathrm{wl}}$ and obtain

$E_{1}=\frac{c_{H}\left(\Delta_{\mathrm{eTa}}\left(T_{1}-T_{\mathrm{a}}\right)+P_{\mathrm{was}}-P_{\mathrm{wa}}\right)}{\gamma_{\mathrm{v}}}$.

We can now insert the linearised Eqs. (23), (26) and (8) into the energy balance equation (Eq. 1), and solve for leaf tem- 

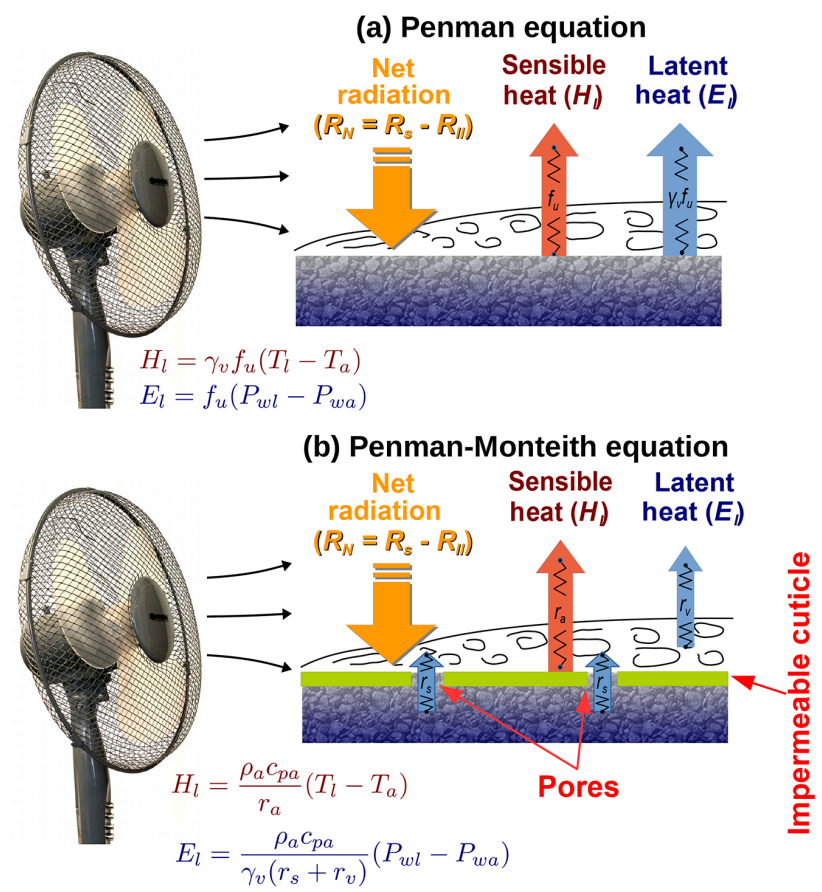

(c) Corrected Penman-Monteith equation

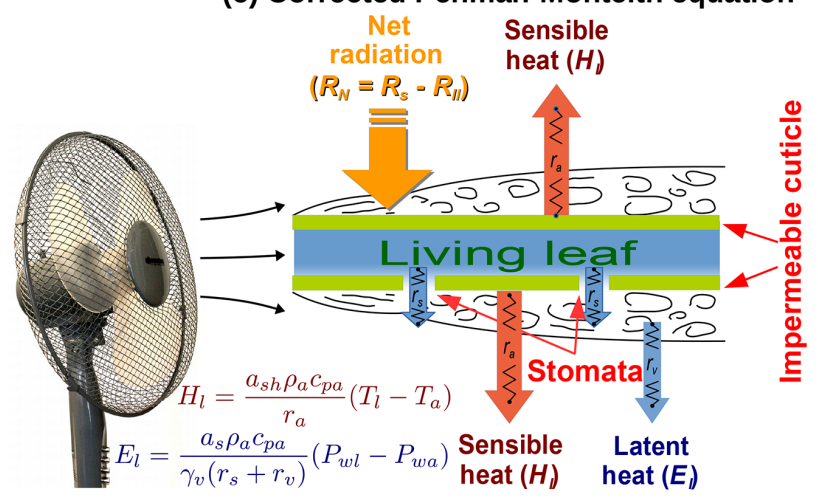

Figure 3. Different representations of energy partitioning into sensible and latent heat flux. (a) Penman equation, where net radiation is partitioned between ground heat flux (not shown), sensible heat flux and latent heat flux at the land surface, affected by boundary layer resistance expressed in wind function $\left(f_{\mathrm{u}}\right)$; (b) PenmanMonteith equation, considering additional stomatal resistance $\left(r_{\mathrm{s}}\right)$; and (c) corrected Penman-Monteith equation for a hypostomatous leaf, where sensible heat flux is emitted from both sides of the leaf $\left(a_{\mathrm{sh}}=2\right)$, while latent heat flux is only released on the abaxial (lower) side of the leaf $\left(a_{\mathrm{S}}=1\right)$.

perature $\left(T_{1}\right)$ to obtain

$$
\begin{aligned}
& T_{1}=\left(R_{\mathrm{s}}+c_{H} T_{\mathrm{a}}+c_{E}\left(\Delta_{\mathrm{eTa}} T_{\mathrm{a}}+P_{\mathrm{wa}}-P_{\mathrm{was}}\right)\right. \\
& \left.+a_{\mathrm{sh}} \epsilon_{1} \sigma\left(3 T_{\mathrm{a}}^{4}+T_{\mathrm{w}}^{4}\right)\right) \frac{1}{c_{H}+c_{E} \Delta_{\mathrm{eTa}}+4 a_{\mathrm{sh}} \epsilon_{1} \sigma T_{\mathrm{a}}^{3}},
\end{aligned}
$$

where the temperature of the surroundings is commonly assumed to equal air temperature $\left(T_{\mathrm{w}}=T_{\mathrm{a}}\right)$. Equation (27) can be reinserted into Eqs. (8), (26) and (23) to obtain analytical expressions for $H_{1}, E_{1}$ and $R_{11}$, respectively, which satisfy the energy balance (Eq. 1). Alternatively, the value of $T_{1}$ obtained from Eq. (27) for specific conditions could be used to calculate any of the energy balance components using the fundamental equations described in Fig. 2. However, in this case, bias in $T_{1}$ due to simplifying assumptions included in the derivation of Eq. (27) could result in an unclosed leaf energy balance $\left(R_{\mathrm{S}}-R_{11}-H_{1}-E_{1} \neq 0\right)$.

\subsection{Comparisons of numerical and analytical models with observations}

Variations in leaf temperature and leaf energy balance components were simulated using a detailed numerical model (Sect. 2.1), and various analytical solutions, including the Penman-Monteith equation (PM; Eq. 19), the MonteithUnsworth equation (MU; Eq. 21), our corrected MonteithUnsworth equation (MUc; Eq. 22) and the analytical solution using linearised net long-wave balance (Rlin, based on Eq. 27). All the above models require similar forcing data, i.e. irradiance or net radiation, air temperature and humidity, wind speed or aerodynamic resistance and stomatal resistance. To compare the adequacy of the different models for capturing the key physical processes, we have used identical environmental forcing in all models, consisting of absorbed short-wave radiation $\left(R_{\mathrm{S}}\right)$, air temperature $\left(T_{\mathrm{a}}\right)$ and vapour pressure $\left(P_{\mathrm{wa}}\right)$, wind speed $\left(v_{\mathrm{w}}\right)$, stomatal conductance $\left(g_{\mathrm{sw}}\right)$ and characteristic length of the leaf $\left(L_{1}\right)$. Wind speed and $L_{1}$ were used to calculate the one-sided convective heat transfer coefficient $\left(h_{\mathrm{c}}\right.$, Eq. B10), which is then used to calculate the leaf boundary layer conductance for water vapour $\left(g_{\mathrm{bw}}\right.$, Eq. B2) in the numerical model. The value of $h_{\mathrm{c}}$ is converted to $r_{\mathrm{a}}$ in the PM equation using Eq. (B51), whereas in our new analytical models $c_{H}=a_{\mathrm{sh}} h_{\mathrm{c}}$. In those models that do not consider feedbacks between leaf temperature and net radiation, i.e. PM, MU and MUc, we assumed that net radiation equals the absorbed short-wave radiation, i.e. $R_{\mathrm{N}}=R_{\mathrm{S}}($ p. 79 in Monteith and Unsworth, 2013). For verification of the results using experimental data, we designed a new experimental set-up, as described below. The forcing corresponding to each experimental data point was used in the different models as described above, producing a simulation data point by each model for each observation data point. Independent calculation of plausible ranges of stomatal resistance or conductance $\left(r_{\mathrm{s}}=1 / g_{\mathrm{sw}}\right)$ is described below, and from within these plausible ranges, we chose values that led to best possible reproduction of the data by the numerical model.

\section{Experimental set-up}

To separate the physical aspects of leaf energy and gas exchange from complex biological control, we used artificial leaves with laser-perforated surfaces representing fixed stom- 


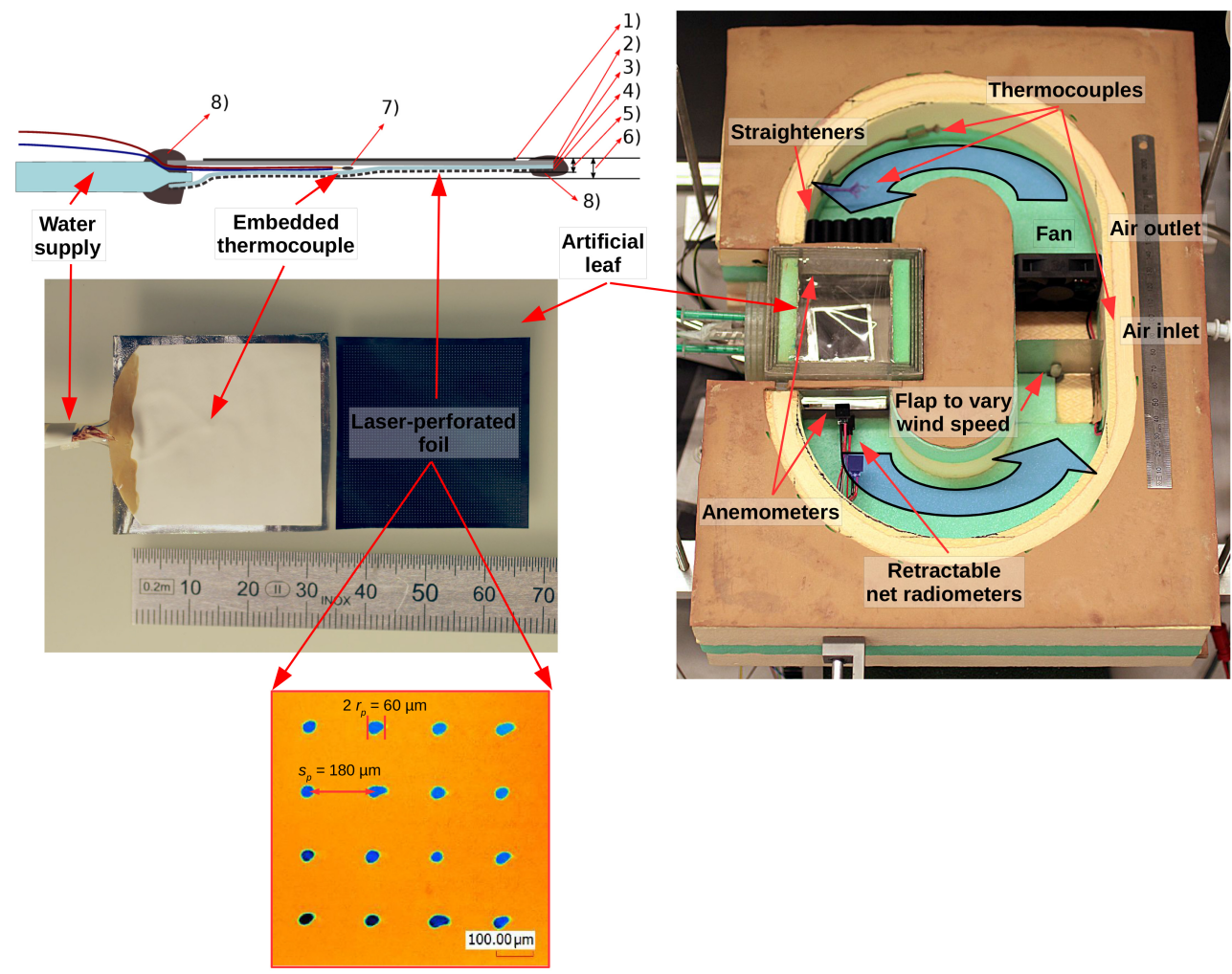

Figure 4. Artificial leaf and wind tunnel. (a): cross section of artificial leaf; (b): leaf image before full assembly; (c): topography of laserperforated foil with $60 \mu \mathrm{m}$ pore diameter and $180 \mu \mathrm{m}$ spacing; (d): wind tunnel. The following are indicated in Panel (a): (1) black aluminium tape $(0.05 \mathrm{~mm}$ thick); (2) aluminium tape $(0.08 \mathrm{~mm})$; (3) absorbent filter paper $(0.1-0.2 \mathrm{~mm})$; (4) laser-perforated foil $(0.01-0.05 \mathrm{~mm})$; (5) min. leaf thickness: $0.3-0.4 \mathrm{~mm}$; (6) max. leaf thickness: 0.35-0.65 mm; (7) thermocouple; (8) glue.

atal apertures and continuous water supply monitored by micro-flow sensors (Fig. 4a-c). We further constructed a specialised insulated leaf wind tunnel (Fig. 4d) permitting full control of atmospheric conditions including air temperature, humidity, irradiance and wind speed and allowing direct measurement of all leaf energy balance components independently, including net radiation latent and sensible heat flux. A detailed documentation of the leaf wind tunnel and the artificial leaves along with the relevant thermodynamic calculations has been submitted as a technical note to HESS (Schymanski et al., 2016).

\subsection{Artificial leaves}

The artificial leaves were constructed of a core made of porous filter paper (Whatman no. 41), glued onto aluminium tape and connected to a water supply by a thin tube, flattened at one end and tightly glued between the aluminium foil and the filter paper, using Araldite epoxy resin (Fig. 4a-c). Along with the water supply tube, a thin copper-constantan thermocouple (TG-TI-40) was placed between the filter paper and the adhesive aluminium tape. The water supply was connected to a high-resolution liquid flow metre (SLI-0430, Sensirion AG, Staefa, Switzerland) and a water supply with a water table $1-3 \mathrm{~cm}$ below the position of the leaf, to ensure that the liquid flow did not exceed the transpiration rate while maintaining minimum head loss along the flow path.

Different laser perforations were performed by Ralph Beglinger (Lasergraph AG, Würenlingen, Switzerland), Robert Voss (ETH Zurich, Switzerland) and Rolf Brönnimann (EMPA, Zurich, Switzerland), and the geometry of laser perforations was measured using a confocal laser scanning microscope (CLSM VK-X200, Keyence, Osaka, Japan). See Fig. A2 for examples.

The stomatal conductance resulting from a particular perforation size and density was computed following the derivations presented by Lehmann and Or (2015), assuming that the stomatal conductance results from two resistances in a series: the throat resistance $\left(r_{\mathrm{sp}}\right)$, resulting from the width of the perforation and the thickness of the perforated foil, and the vapour shell resistance $\left(r_{\mathrm{vs}}\right)$, resulting from the size and spacing of the stomata, which can be understood as the resistance related to distribution of the point-source water vapour over the entire one-sided leaf boundary layer. We hereby neglect any internal resistance (termed "end correction" by Lehmann and Or, 2015), as we assume that the wet filter paper has direct contact with the perforated foil. The relevant equations are described in Appendix B10. 


\subsection{Leaf wind tunnel}

Leaf energy and gas exchange were measured in a thermally insulated wind tunnel with full control over energy and mass exchange (Fig. 4). The wind tunnel is circular, with two straight sections of $25 \mathrm{~cm}$ length each, a fan in one of the straight sections and a transparent window and leaf holder in the opposite straight channel. The fan circulates the wind as indicated by the arrows in Fig. 4d, subjecting it to controlled wind conditions. The wind tunnel features an air inlet just before the fan and an air outlet just after the fan, where the air is assumed to be well mixed across the tunnel cross section. In this way, leaf gas exchange can be deduced from the concentration difference between the incoming and outgoing air and the controlled flow rate of air into the wind tunnel. For this purpose, the incoming air was supplied by a humidifier providing prescribed vapour pressure and flow rate.

The sensible heat flux $\left(H_{1}\right)$ was deduced from the chamber energy balance by computing the amount of heat exchanged with the surroundings through the exchange of air and subtracting the amount of heat added by the fan. Since the fan was placed inside the chamber, the amount of heat it injected was assumed to be equal to its power consumption, which was kept constant by a programmable power controller, while wind speed was varied by adjusting the position of a wing in the flow path (Fig. 4) and monitored using a miniature thermal flow sensor. A stack of $3 \mathrm{~cm}$ long plastic straws in the flow path was used to reduce spiralling of the air flow caused by the rotating fan. The main wind tunnel was built out of foamed insulation material, while the leaf chamber itself had two layers of polypropylene foil on each side (above and below the leaf) to permit the transmission of short-wave and long-wave radiation while minimising conductive heat transfer (see position of the artificial leaf in Fig. 4). We used retractable miniature net radiation sensors to periodically measure the net radiative load on the leaf. Copper-constantan thermocouples were placed in the air stream upstream and downstream of the leaf chamber, lightly inserted into the wind tunnel wall on the inside and the outside of the chamber, and in the duct through which air was supplied to the wind tunnel by an external humidifier, providing a flow rate of up to $10 \mathrm{~L} \mathrm{~min}^{-1}$ and controlled air temperature and dew point.

The leaf wind tunnel was used to measure steady-state conditions under given forcing (air temperature, humidity, wind speed and irradiance). Sensible heat exchange between the leaf and the surrounding air was computed from total chamber heat exchange, using monitored flow rate and temperature of incoming and outgoing air (Fig. 5). The relevant thermodynamic calculations are presented in a separate technical note (Schymanski et al., 2016).

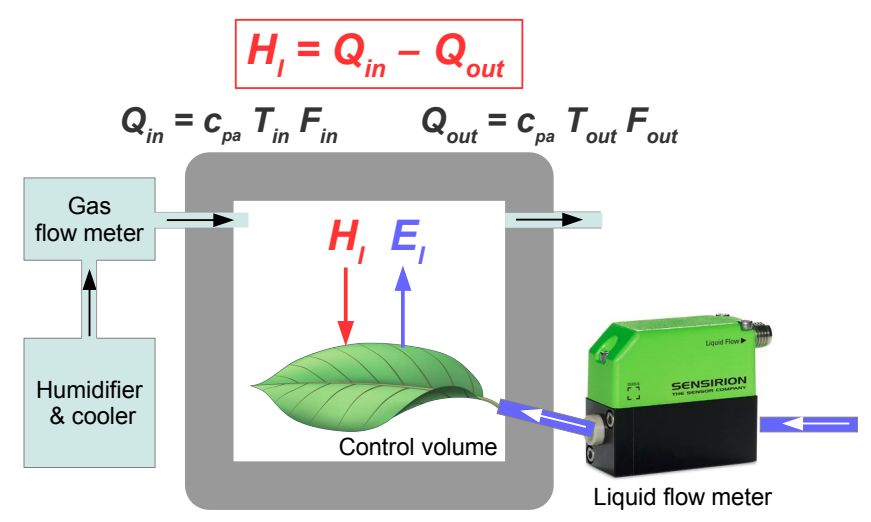

Figure 5. Simplified energy balance of insulated wind tunnel. Latent heat flux $\left(E_{1}\right)$ is calculated from liquid flow rate into leaf, sensible heat flux $\left(H_{1}\right)$ is calculated from difference in heat content of incoming and outgoing air $\left(c_{\mathrm{pa}}\right.$ : heat capacity of air; $T_{\mathrm{in}}, T_{\mathrm{out}}$ : air temperatures of incoming and outgoing air; $F_{\text {in }}, F_{\text {out }}$ : incoming and outgoing air flow rates).

Table 1. Perforation characteristics and resulting stomatal conductances, computed using Eqs. (B55) and (B56), following the procedure described in the Appendix, Sect. B10. Foil thickness is $25 \mu \mathrm{m}$.

\begin{tabular}{lccc}
\hline $\begin{array}{l}\text { Pore density } \\
\mathrm{mm}^{-2}\end{array}$ & $\begin{array}{c}\text { Pore area } \\
\mu \mathrm{m}^{-2}\end{array}$ & $\begin{array}{c}\text { Pore radius } \\
\mu \mathrm{m}\end{array}$ & $\begin{array}{c}g_{\text {sw }} \\
\mathrm{m} \mathrm{s}^{-1}\end{array}$ \\
\hline $27.3-38.2$ & $710-1572$ & $15-22$ & $0.022-0.046$ \\
$7.1-7.8$ & $890-1886$ & $16-24$ & $0.006-0.012$ \\
\hline
\end{tabular}

$g_{\text {Sw }}$ : calculated stomatal conductance.

\section{Results}

\subsection{Correspondence between experimental results and numerical model}

Experiments were performed for various artificial leaves with different stomatal conductances under varying air humidity or varying wind speed, in the absence of short-wave radiation. Stomatal conductance was deduced form confocal laser scanning microscope (CLSM) images of the perforated foils, as described above. The ranges of stomatal geometries and deduced conductances for the two different leaves presented here are given in Table 1. A more detailed analysis of correspondence between experimental results obtained for a larger variety of artificial leaves and the numerical model are presented in a technical note (Schymanski et al., 2016). Here, we only present selected experiments that highlight systematic differences between the various analytical solutions, the numerical model and observations.

The numerical model reproduced observed sensible and latent heat fluxes very accurately (Fig. 6) using stomatal conductance values within the narrow ranges deduced from CLSM images (Table 1) with no other forms of calibration. 
The experimental conditions and stomatal conductances are given in the figure captions. Observed net radiation $\left(R_{\text {nleaf }}\right)$ was a little bit below the sum of observed latent and sensible heat fluxes $\left(E_{1}+H_{1}\right.$, Fig. 6), suggesting that the energy balance was not entirely closed. Simulated net radiation ( $\left.R_{\text {nleaf }}=R_{\mathrm{S}}-R_{11}\right)$ was in between the observed $R_{\text {nleaf }}$ and the observed $E_{1}+H_{1}$. Consistent with Fig. 1 , the net radiative exchange was not sensitive to wind speed in Fig. 6a, while $E_{1}$ and $H_{1}$ responded strongly (in opposite directions).

\subsection{Performance of analytical leaf gas exchange and energy balance models}

The analytical models generally underestimated latent heat flux, but the model based on linearised $R_{11}$ (Rlin) showed very little bias and closely reproduced the observed latent and sensible heat fluxes, as it permitted calculation of the net long-wave component (in contrast with PM, MU and MUc expressions that assumed $R_{11}=0$ ). The calculations based on the Penman-Monteith equation significantly underestimated latent heat flux, especially at high stomatal conductances (PM values almost 50\% lower than the observed values in Fig. 7). The Monteith-Unsworth (MU) equation produced an even stronger underestimation of latent heat flux in our results, whereas our corrected Monteith-Unsworth (MUc) equation was a lot closer to the observed heat fluxes than either the MU or the PM equations. However, only Eq. (27) (Rlin) was able to capture the asymmetry between latent and sensible heat fluxes caused by net absorption of long-wave radiation, as all the other calculations were based on the assumption of zero radiative exchange $\left(R_{11}=0\right)$, i.e. $H_{1}=-E_{1}$. Our results suggest that the omission of the long-wave radiative feedback (MUc) resulted in a much smaller effect than the omission of two-sided sensible heat exchange (PM, $\mathrm{MU})$, compared to the most comprehensive analytical solution (Rlin) and observations.

Since we were not able to systematically assess the effects of irradiance and air temperature in our lab experiments, we conducted a numerical experiment where we compared simulations by the numerical model with simulations by the best analytical model and the PM equation. The results shown in Fig. 8 suggest that our new analytical solution (Eq. 27) behaves very similarly to the numerical model, whereas the PM equation misrepresents the sensitivities of latent and sensible heat fluxes to both irradiance and air temperature.

\section{Discussion}

This age values usefulness more highly than correctness, and the making of money more highly than both. In fact, there is definitely something suspect about an examiner who would bother at all with whether an idea is correct or not. (Raupach and Finnigan, 1988) (a) 35 perforations $\mathrm{mm}^{-2}$

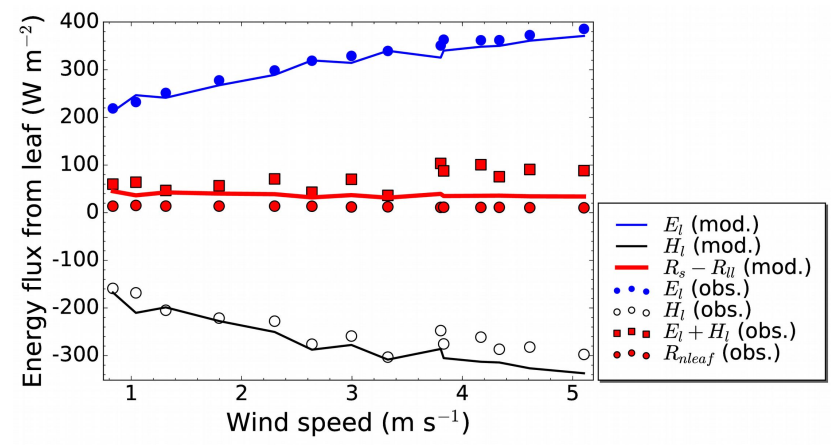

(b) 35 perforations $\mathrm{mm}^{-2}$

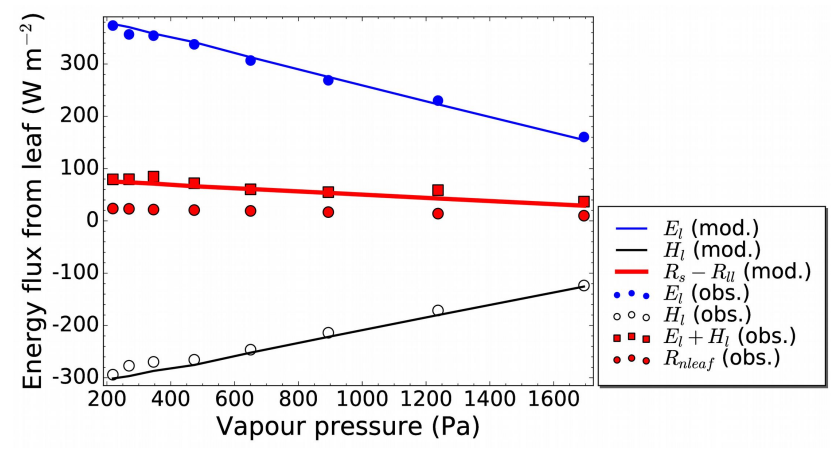

(c) 7 perforations $\mathrm{mm}^{-2}$

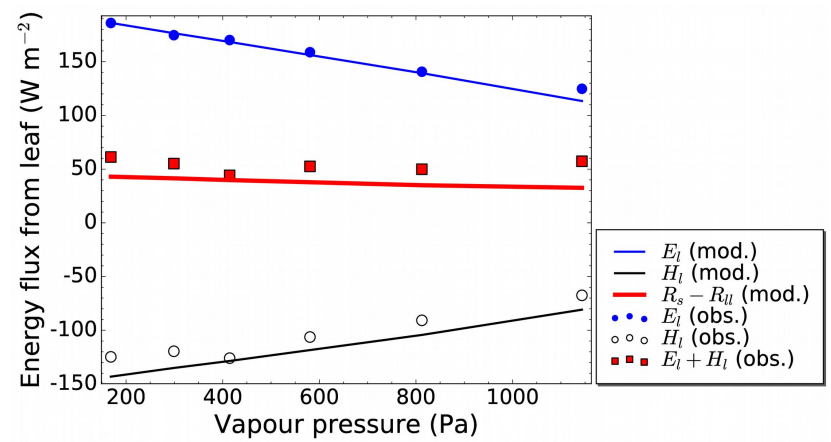

Figure 6. Numerical simulations vs. observed fluxes of sensible, latent and radiative heat in response to varying wind speed and vapour pressure. Numerical model results (lines) are based on observed boundary conditions representative of observations (dots). The boundary conditions are summarised as follows: (a) $g_{\mathrm{sw}}=0.042 \mathrm{~m} \mathrm{~s}^{-1} ; R_{\mathrm{S}}=0 ; T_{\mathrm{a}}=295.0-296.5 \mathrm{~K} ; P_{\mathrm{wa}}=1187-$ $1278 \mathrm{~Pa} ;$ (b) $g_{\mathrm{sw}}=0.035 \mathrm{~m} \mathrm{~s}^{-1} ; \quad R_{\mathrm{S}}=0 ; T_{\mathrm{a}}=295.7-296.0 \mathrm{~K}$; $v_{\mathrm{W}}=1.0 \mathrm{~m} \mathrm{~s}^{-1} ; \quad$ (c) $g_{\mathrm{sw}}=0.0065 \mathrm{~m} \mathrm{~s}^{-1} ; R_{\mathrm{S}}=0 ; T_{\mathrm{a}}=296.1-$ $296.7 \mathrm{~K} ; v_{\mathrm{W}}=0.7 \mathrm{~m} \mathrm{~s}^{-1} . g_{\mathrm{sw}}$ : stomatal conductance; $T_{\mathrm{a}}$ : air temperature; $P_{\mathrm{wa}}$ : vapour pressure; $E_{1}$ : latent heat flux; $H_{1}$ : sensible heat flux; $R_{\mathrm{S}}$ : absorbed short-wave radiation; $R_{11}$ : net emitted longwave radiation; $R_{\text {nleaf }}=R_{\mathrm{S}}-R_{11}$. 
(a) 35 perforations $\mathrm{mm}^{-2}$

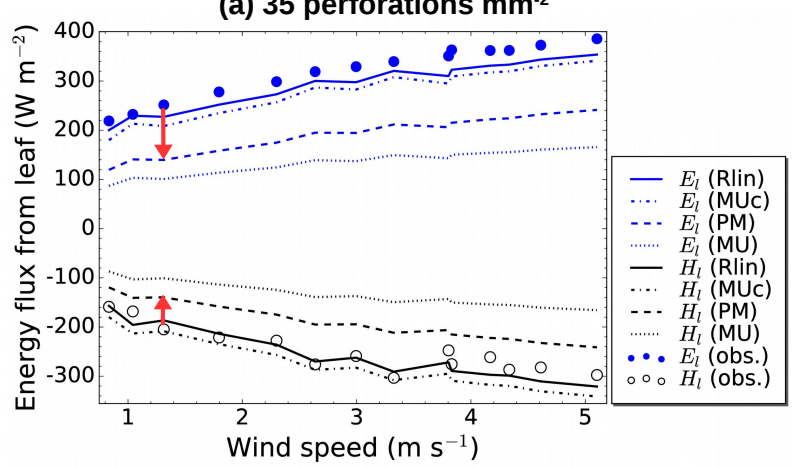

(b) 35 perforations $\mathrm{mm}^{-2}$

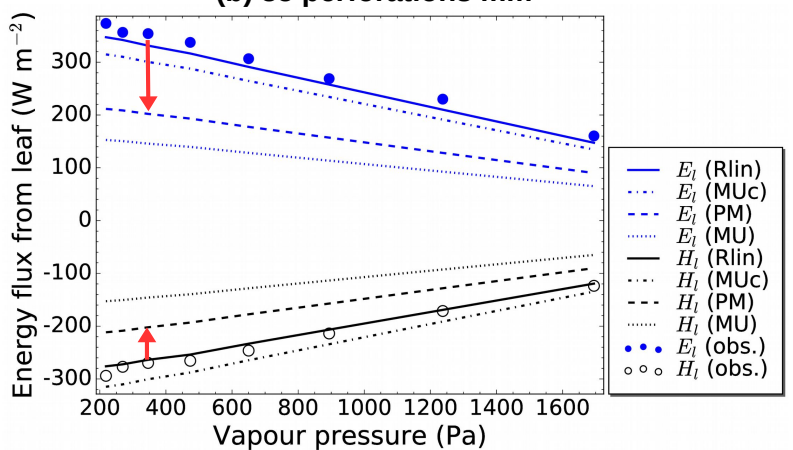

(c) 7 perforations $\mathrm{mm}^{-2}$

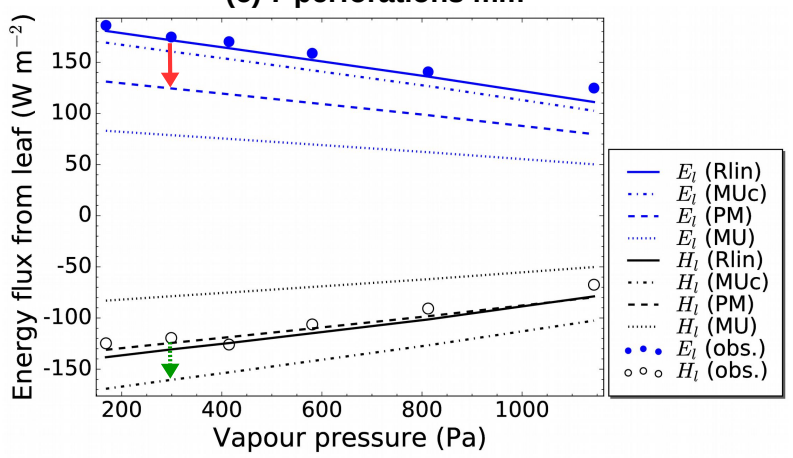

Figure 7. Analytical simulations vs. observed fluxes of sensible and latent heat in response to varying wind and vapour pressure. Numerical model results (lines) are based on observed boundary conditions representative of observations (dots). Conditions are the same as in Fig. 6. $E_{1}$ : latent heat flux; $H_{1}$ : sensible heat flux; Rlin: based on linearised long-wave balance (Eq. 27); MUc: corrected MonteithUnsworth equation (Eq. 22); PM: Penman-Monteith equation (Eq. 19); MU: Monteith-Unsworth equation (Eq. 21). Red arrows indicate the magnitudes of biases in the PM equation; the dashed green arrow marks the maximum bias in sensible heat flux in the MUc equation for the experimental conditions.

The widespread use of the PM equation is mainly due to its simplicity and usefulness, the latter of which is contingent on its ability to accurately represent the sensitivity of evapotranspiration to atmospheric variables and surface properties (boundary layer and bulk stomatal conductances). (a) Varying radiation $\left(T_{a}=295 \mathrm{~K}\right)$

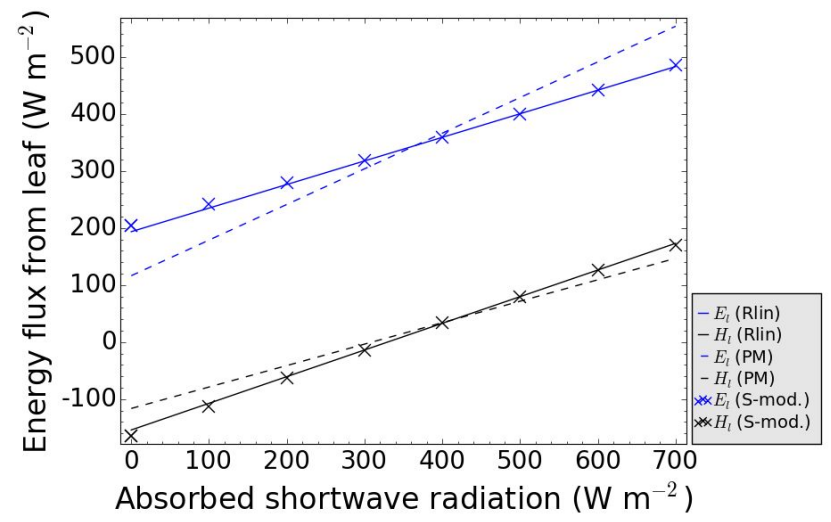

(b) Varying air temperature $\left(R_{s}=350 \mathrm{~W} \mathrm{~m}^{-2}\right)$

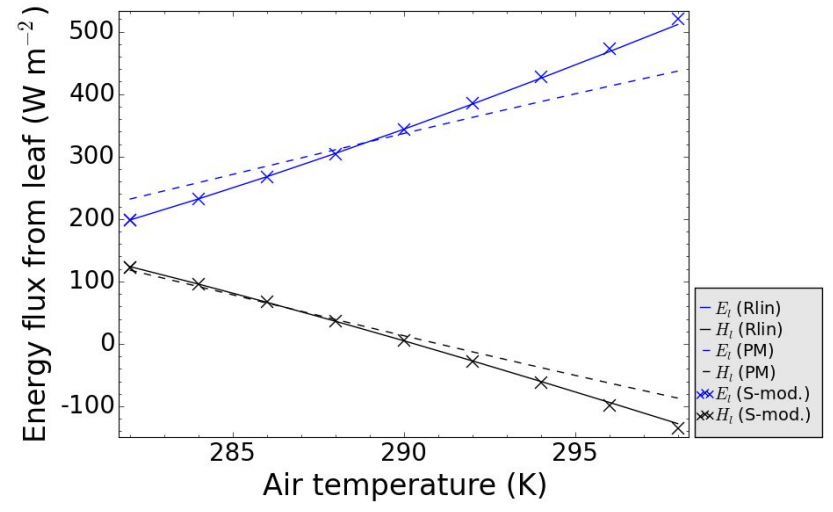

Figure 8. Numerical vs. analytical simulations of sensible and latent heat in response to varying irradiance and air temperature. Crosses represent numerical solution of leaf energy balance model (S-mod.), solid lines our new analytical solution based on linearised longwave balance (Rlin; Eq. 27) and dashed lines the Penman-Monteith equation (PM; Eq. 19). Simulation conditions: $g_{\mathrm{sw}}=0.045 \mathrm{~m} \mathrm{~s}^{-1}$; $P_{\mathrm{wa}}=1300 \mathrm{~Pa} ; v_{\mathrm{w}}=1 \mathrm{~m} \mathrm{~s}^{-1} \cdot g_{\mathrm{sw}}:$ stomatal conductance; $T_{\mathrm{a}}:$ air temperature; $P_{\text {wa }}$ : vapour pressure; $E_{1}$ : latent heat flux; $H_{1}$ : sensible heat flux; $R_{\mathrm{S}}$ : absorbed short-wave radiation.

In our rederivation and subsequent analyses, we have identified two errors in the PM equation and in the "corrected" MU formulation by Monteith and Unsworth (2013). Both formulations are based on evaporation from a soil surface, which exchanges sensible and radiative heat only on one side, whereas planar leaves have two sides exposed to the surrounding air. Failure to recognise this omission has led to a second error in the MU formulation, where an additional reduction to transpiration was introduced to represent leaves that exchange water vapour from one side only. For a leaf, the energy for transpiration in darkness is mainly supplied by sensible heat flux (on both sides), which increases with increasing wind speed. In contrast, the energy for evaporation from a soil surface in darkness is supplied by sensible heat on the evaporating surface only (and by soil heat flux from below). The neglect of the additional exchange of sensible heat on the second side of the leaf in the PM and MU models 
led to significant underestimation of the observed transpiration rates in our experiments, where the sensible heat flux is the main source of energy for transpiration (in the absence of short-wave radiation). Note, however, that the bias is not constant and not always negative. As illustrated in Fig. 8, the negative bias decreases with increasing irradiance or air temperature, goes to 0 at a certain combination of temperature and irradiance and then becomes positive at higher values of irradiance and/or temperature. This is because under conditions where the leaf temperature is lower than ambient, sensible heat flux is a source of energy for transpiration, whereas under conditions where the leaf is warmer than the air, sensible heat flux competes for energy with transpiration. The omission of sensible heat exchange by the second leaf surface has therefore the most drastic effects when leaf temperature most strongly deviates from air temperature. It may also be noteworthy in this context that the expression for aerodynamic resistance $\left(r_{\mathrm{a}}\right)$ given by Monteith (1965, Eq. 14) has been pointed out by other authors to result in heat transfer 2.5 times higher than expected if interpreted as a onesided resistance (Parlange et al., 1971). This may have arisen from the confusion about one-sided vs. two-sided energy exchange. Our experimental results clearly illustrate that the inconsistencies we found in the PM and MU equations are not just semantic, but actually lead to very significant biases in simulated transpiration rates for known stomatal resistance, which would alternatively lead to biases in deduced resistance for known transpiration rates. The results further illustrate that our correction for two-sided leaves improves reproduction of leaf-scale measurements tremendously (MUc vs. PM in Fig. 7), but additional consideration of the surface temperature-long-wave emission feedback (Eq. 27 and Rlin in Fig. 7) is also important to accurately capture the characteristics of the leaf energy balance, particularly the sensible heat flux.

Although the upscaling of a physically based leaf-scale model to a canopy or land surface is fraught with various challenges, including characterisation of the stomatal or canopy conductance, canopy-scale boundary layer conductance, consideration of canopy storage and distinction between radiative and aerodynamic surface temperatures (Monteith, 1965; Tanner and Fuchs, 1968; Jarvis and McNaughton, 1986; Raupach, 1995; Mallick et al., 2013, 2016), we believe that care must be taken to start off with the correct leaf-scale model. In this context, we wish to point out that Monteith (1965) referred to a single leaf when deriving the PM equation (evident in the abstract and from Page 208 onwards in his paper), and that the use of the PM equation at canopy scale is commonly motivated in the context of a big leaf analogy or by aggregation of many representative leaves, implying that the physics valid for a leaf is also valid for a canopy (e.g. Lhomme et al., 2012; Verhoef and Allen, 2000). Therefore, the omission of the second side of a leaf when Monteith (1965) used the Penman equation as a basis for his derivation is likely relevant when representing canopy fluxes using the PM equation.

In the present study, we have developed an experimental set-up allowing to control all relevant boundary conditions at the leaf scale, including stomatal conductance, and measuring (to our knowledge, for the first time) all components of the leaf energy balance. In contrast to previous tests of the PM equation, which were conducted at the canopy scale, where boundary layer and canopy conductances could not be measured directly, we have been able to greatly constrain model parametrisation by independent measurements of stomatal conductance. This has led to the discovery that the PM equation, in its original formulation and common use, does not accurately represent leaf-scale processes. Our newly derived analytical solutions (Eqs. 27 and 22) are able to not only more accurately reproduce leaf-scale sensible and latent heat fluxes, but they also allow direct calculation of leaf temperature, which could be used as an additional diagnostic variable at the canopy scale and potentially improve remotesensing-based evaporation products.

Given the widespread and successful use of the PM equation, the question arises whether common practice, which relies on parameterisation by fitting resistance terms that provide a match with observations, somehow compensates for the errors we identified in the present study. The answer is "yes and no". As shown in Fig. 8, there are certain conditions for which the PM equation and the corrected solutions yield very similar results, and one could easily obtain a much closer match to the experimental results by fitting significantly larger values for $r_{\mathrm{a}}$ and $r_{\mathrm{s}}$ in the PM equation than those estimated from diffusive resistance of perforated surfaces (the laser perforations in our artificial leaves). This may also explain the lack of general bias in PM-estimated transpiration rates when applied at the canopy scale (e.g. Langensiepen et al., 2009). However, the sensitivity of latent and sensible heat flux to changing atmospheric conditions (e.g. short-wave irradiance and air temperature) deduced from the PM equation would clearly be different than the trends produced by the corrected equations and numerical simulations (Fig. 8). This suggests that use of the PM equation for projections under future climate change scenarios could lead to a bias in the results. This potential source of bias could be reduced using the corrected equation presented in this study (irrespective of the estimated resistance values fitted for a canopy).

\section{Conclusions}

In this study, we revisit the governing equations for the exchange of water vapour and energy between a planar leaf and a surrounding air stream under forced convection. We derived general analytical solutions for steady-state sensible and latent heat fluxes from a leaf and the corresponding leaf temperature (Eqs. 10-12) based on the approach by Pen- 
man (1952). The general equation permits comparison between different analytical solutions available in the literature by substituting appropriate formulations of the sensible and latent heat transfer coefficients. Our analysis reveals that the Penman-Monteith equation (Eq. 19), even with its modification by Monteith and Unsworth (2013) (Eq. 21) is not accurate for a typical planar leaf due to omission of the radiative and sensible heat fluxes from one side of a leaf. We demonstrated how our general solution can be used to obtain a more consistent representation of leaf energy and gas exchange, in agreement with leaf-scale experimental data (using artificial leaves). We propose that the same approach could prove useful to derive a more accurate canopy-scale representation of latent and sensible heat fluxes, considering their coupling with radiative exchange and ground heat flux. The new generalised leaf-scale equations offer a promise for more consistent responses of latent and sensible heat fluxes to changes in atmospheric forcing in future climates than the responses predicted by the original PM equation (due to the omissions therein).

\section{Code and data availability}

All code and data used to generate the results presented in this paper are available online at doi:10.5281/zenodo.241259 (Schymanski, 2017). 
Appendix A: Additional tables and figures

Table A1. Table of symbols and standard values used in this paper. All area-related variables are expressed per unit leaf area.

\begin{tabular}{|c|c|c|}
\hline Variable & Description (value) & Units \\
\hline$A_{\mathrm{p}}$ & Cross-sectional pore area & $\mathrm{m}^{2}$ \\
\hline$a_{\mathrm{S}}$ & $\begin{array}{l}\text { Fraction of one-sided leaf area covered by stomata ( } 1 \text { if stomata are } \\
\text { on one side only, } 2 \text { if they are on both sides) }\end{array}$ & 1 \\
\hline$a_{\mathrm{sh}}$ & Fraction of projected area exchanging sensible heat with the air (2) & 1 \\
\hline$\alpha_{\mathrm{a}}$ & Thermal diffusivity of dry air & $\mathrm{m}^{2} \mathrm{~s}^{-1}$ \\
\hline$\beta_{\mathrm{B}}$ & Bowen ratio (sensible / latent heat flux) & 1 \\
\hline$c_{E}$ & Latent heat transfer coefficient & $\mathrm{JPa}^{-1} \mathrm{~m}^{-2} \mathrm{~s}^{-1}$ \\
\hline$c_{H}$ & Sensible heat transfer coefficient & $\mathrm{J} \mathrm{K}^{-1} \mathrm{~m}^{-2} \mathrm{~s}^{-1}$ \\
\hline$c_{\mathrm{pa}}$ & Specific heat of dry air (1010) & $\mathrm{J} \mathrm{K}^{-1} \mathrm{~kg}^{-1}$ \\
\hline$C_{\mathrm{wa}}$ & Concentration of water in the free air & $\mathrm{mol} \mathrm{m}^{-3}$ \\
\hline$C_{\mathrm{wl}}$ & Concentration of water in the leaf air space & $\mathrm{mol} \mathrm{m}^{-3}$ \\
\hline$d_{\mathrm{p}}$ & Pore depth & $\mathrm{m}$ \\
\hline$D_{\mathrm{va}}$ & Binary diffusion coefficient of water vapour in air & $\mathrm{m}^{2} \mathrm{~s}^{-1}$ \\
\hline$\Delta_{\mathrm{eTa}}$ & Slope of saturation vapour pressure at air temperature & $\mathrm{Pa} \mathrm{K}^{-1}$ \\
\hline$E_{1}$ & Latent heat flux from leaf & $\mathrm{J} \mathrm{m}^{-2} \mathrm{~s}^{-1}$ \\
\hline$E_{1, \mathrm{~mol}}$ & Transpiration rate in molar units & $\mathrm{mol} \mathrm{m}^{-2} \mathrm{~s}^{-1}$ \\
\hline$E_{\mathrm{W}}$ & Latent heat flux from a wet surface & $\mathrm{J} \mathrm{m}^{-2} \mathrm{~s}^{-1}$ \\
\hline$\epsilon$ & Water-to-air molecular weight ratio $(0.622)$ & 1 \\
\hline$\epsilon_{1}$ & Long-wave emissivity of the leaf surface (1.0) & 1 \\
\hline$f_{\mathrm{u}}$ & Wind function in Penman approach, $f(u)$ adapted to energetic units & $\mathrm{JPa}^{-1} \mathrm{~m}^{-2} \mathrm{~s}^{-1}$ \\
\hline$g$ & Gravitational acceleration $(9.81)$ & $\mathrm{m} \mathrm{s}^{-2}$ \\
\hline$g_{\text {bw }}$ & Boundary layer conductance to water vapour & $\mathrm{ms}^{-1}$ \\
\hline$g_{\text {bw,mol }}$ & Boundary layer conductance to water vapour & $\mathrm{mol} \mathrm{m}^{-2} \mathrm{~s}^{-1}$ \\
\hline$g_{\mathrm{sw}}$ & Stomatal conductance to water vapour & $\mathrm{m} \mathrm{s}^{-1}$ \\
\hline$g_{\text {sw,mol }}$ & Stomatal conductance to water vapour & $\mathrm{mol} \mathrm{m}^{-2} \mathrm{~s}^{-1}$ \\
\hline$g_{\text {tw }}$ & Total leaf conductance to water vapour & $\mathrm{m} \mathrm{s}^{-1}$ \\
\hline$g_{\mathrm{tw}, \mathrm{mol}}$ & Total leaf layer conductance to water vapour & $\mathrm{mol} \mathrm{m}^{-2} \mathrm{~s}^{-1}$ \\
\hline$\gamma_{\mathrm{v}}$ & Psychrometric constant & $\mathrm{Pa} \mathrm{K}^{-1}$ \\
\hline$h_{\mathrm{c}}$ & Average one-sided convective transfer coefficient & $\mathrm{J} \mathrm{K}^{-1} \mathrm{~m}^{-2} \mathrm{~s}^{-1}$ \\
\hline$H_{1}$ & Sensible heat flux from leaf & $\mathrm{J} \mathrm{m}^{-2} \mathrm{~s}^{-1}$ \\
\hline$k_{\mathrm{a}}$ & Thermal conductivity of dry air & $\mathrm{JK}^{-1} \mathrm{~m}^{-1} \mathrm{~s}^{-1}$ \\
\hline$k_{\mathrm{dv}}$ & Ratio $D_{\mathrm{va}} / V_{\mathrm{m}}$ & $\mathrm{mol} \mathrm{m}^{-1} \mathrm{~s}^{-1}$ \\
\hline$L_{1}$ & Characteristic length scale for convection (size of leaf) & $\mathrm{m}$ \\
\hline$\lambda_{E}$ & Latent heat of evaporation $(2.45 e 6)$ & $\mathrm{J} \mathrm{kg}^{-1}$ \\
\hline$M_{\mathrm{N}_{2}}$ & Molar mass of nitrogen $(0.028)$ & $\mathrm{kg} \mathrm{mol}^{-1}$ \\
\hline$M_{\mathrm{O}_{2}}$ & Molar mass of oxygen $(0.032)$ & $\mathrm{kg} \mathrm{mol}^{-1}$ \\
\hline$M_{\mathrm{W}}$ & Molar mass of water $(0.018)$ & $\mathrm{kg} \mathrm{mol}^{-1}$ \\
\hline$N_{G} r_{L}$ & Grashof number & 1 \\
\hline$N_{L e}$ & Lewis number & 1 \\
\hline$n_{\mathrm{MU}}$ & $n=2$ for hypostomatous, $n=1$ for amphistomatous leaves & 1 \\
\hline$N_{N u_{L}}$ & Nusselt number & 1 \\
\hline$n_{\mathrm{p}}$ & Pore density & $\mathrm{m}^{-2}$ \\
\hline$N_{P r}$ & Prandtl number $(0.71)$ & 1 \\
\hline$N_{R e_{\mathrm{c}}}$ & Critical Reynolds number for the onset of turbulence & 1 \\
\hline$N_{R e_{L}}$ & Reynolds number & 1 \\
\hline$N_{S h_{L}}$ & Sherwood number & 1 \\
\hline$v_{\mathrm{a}}$ & Kinematic viscosity of dry air & $\mathrm{m}^{2} \mathrm{~s}^{-1}$ \\
\hline$P_{\mathrm{a}}$ & Air pressure & $\mathrm{Pa}$ \\
\hline$P_{\mathrm{N}_{2}}$ & Partial pressure of nitrogen in the atmosphere & $\mathrm{Pa}$ \\
\hline$P_{\mathrm{O}_{2}}^{2}$ & Partial pressure of oxygen in the atmosphere & $\mathrm{Pa}$ \\
\hline
\end{tabular}


Table A1. Continued.

\begin{tabular}{|c|c|c|}
\hline Variable & Description (value) & Units \\
\hline$P_{\mathrm{wa}}$ & Vapour pressure in the atmosphere & $\mathrm{Pa}$ \\
\hline$P_{\mathrm{was}}$ & Saturation vapour pressure at air temperature & $\mathrm{Pa}$ \\
\hline$P_{\mathrm{wl}}$ & Vapour pressure inside the leaf & $\mathrm{Pa}$ \\
\hline$r_{\mathrm{a}}$ & $\begin{array}{l}\text { One-sided boundary layer resistance to heat transfer } \\
\left(r_{\mathrm{H}} \text { in Monteith and Unsworth }(2013, \text { p. } 231)\right)\end{array}$ & $\mathrm{s} \mathrm{m}^{-1}$ \\
\hline$r_{\mathrm{bw}}$ & Boundary layer resistance to water vapour, inverse of $g_{\mathrm{bw}}$ & $\mathrm{s} \mathrm{m}^{-1}$ \\
\hline$R_{11}$ & Long-wave radiation away from leaf & $\mathrm{J}^{-2} \mathrm{~s}^{-1}$ \\
\hline$R_{\mathrm{mol}}$ & Molar gas constant $(8.314472)$ & $\mathrm{J} \mathrm{K}^{-1} \mathrm{~mol}^{-1}$ \\
\hline$r_{\mathrm{p}}$ & Pore radius (for ellipsoidal pores, half the pore width) & $\mathrm{m}$ \\
\hline$R_{\mathrm{S}}$ & Solar short-wave flux & $\mathrm{J} \mathrm{m}^{-2} \mathrm{~s}^{-1}$ \\
\hline$r_{\mathrm{S}}$ & Stomatal resistance to water vapour (Monteith and Unsworth, 2013, p. 231) & $\mathrm{s} \mathrm{m}^{-1}$ \\
\hline$r_{\mathrm{sp}}$ & Diffusive resistance of a stomatal pore & $\mathrm{s} \mathrm{m}^{2} \mathrm{~mol}^{-1}$ \\
\hline$r_{\mathrm{SW}}$ & Stomatal resistance to water vapour, inverse of $g_{\mathrm{sw}}$ & $\mathrm{s} \mathrm{m}^{-1}$ \\
\hline$r_{\mathrm{tw}}$ & Total leaf resistance to water vapour, $r_{\mathrm{bv}}+r_{\mathrm{sv}}$ & $\mathrm{sm}^{-1}$ \\
\hline$r_{\mathrm{V}}$ & Leaf BL resistance to water vapour; Monteith and Unsworth, 2013, Eq. 13.16 & $\mathrm{~s} \mathrm{~m}^{-1}$ \\
\hline$r_{\mathrm{Vs}}$ & Diffusive resistance of a stomatal vapour shell & $\mathrm{s} \mathrm{m}^{2} \mathrm{~mol}^{-1}$ \\
\hline$\rho_{\mathrm{a}}$ & Density of dry air & $\mathrm{kg} \mathrm{m}^{-3}$ \\
\hline$\rho_{\mathrm{al}}$ & Density of air at the leaf surface & $\mathrm{kg} \mathrm{m}^{-3}$ \\
\hline$S$ & Factor representing stomatal resistance in Penman (1952) & 1 \\
\hline$s_{\mathrm{p}}$ & Spacing between stomata & $\mathrm{m}$ \\
\hline$\sigma$ & Stefan-Boltzmann constant $(5.67 e-8)$ & $\mathrm{JK}^{-4} \mathrm{~m}^{-2} \mathrm{~s}^{-1}$ \\
\hline$T_{\mathrm{a}}$ & Air temperature & $\mathrm{K}$ \\
\hline$T_{1}$ & Leaf temperature & $\mathrm{K}$ \\
\hline$T_{\mathrm{W}}$ & Radiative temperature of objects surrounding the leaf & $\mathrm{K}$ \\
\hline$V_{\mathrm{m}}$ & Molar volume of air & $\mathrm{m}^{3} \mathrm{~mol}^{-1}$ \\
\hline$v_{\mathrm{W}}$ & Wind velocity & $\mathrm{ms}^{-1}$ \\
\hline
\end{tabular}

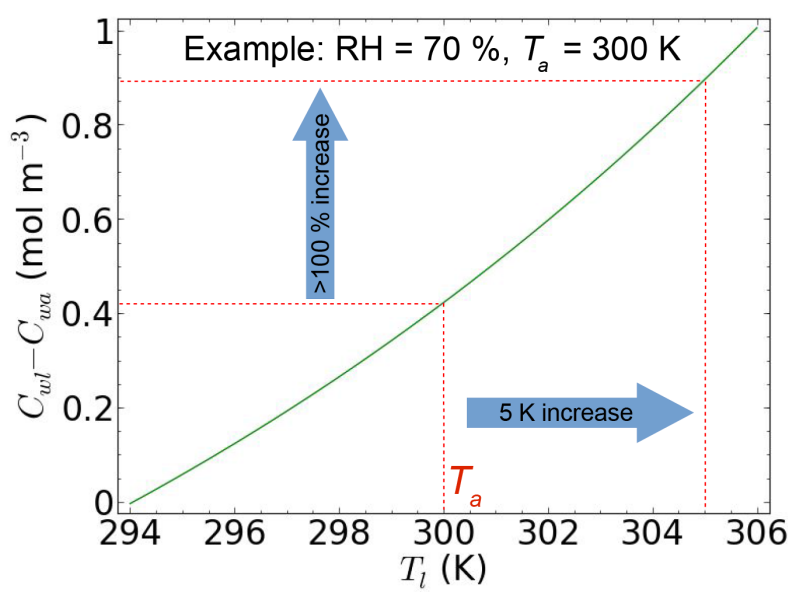

Figure A1. Dependence of the leaf-air water vapour concentration difference $\left(C_{\mathrm{wl}}-C_{\mathrm{wa}}\right)$ on leaf temperature $\left(T_{1}\right)$. In this example, $(70 \%$ relative humidity, $300 \mathrm{~K}$ air temperature $\left(T_{\mathrm{a}}\right)$, the water vapour concentration difference doubles for an increase in leaf temperature by $5 \mathrm{~K}$ relative to air temperature or drops to 0 for a decrease in leaf temperature by $6 \mathrm{~K}$. Plot obtained by inserting Eq. (B5) into Eq. (B4). $C_{\text {wa }}$ was obtained substituting $T_{\mathrm{a}}$ for $T_{1}$ and multiplying Eq. (B5) by the assumed relative humidity of 0.7 . 
(a)

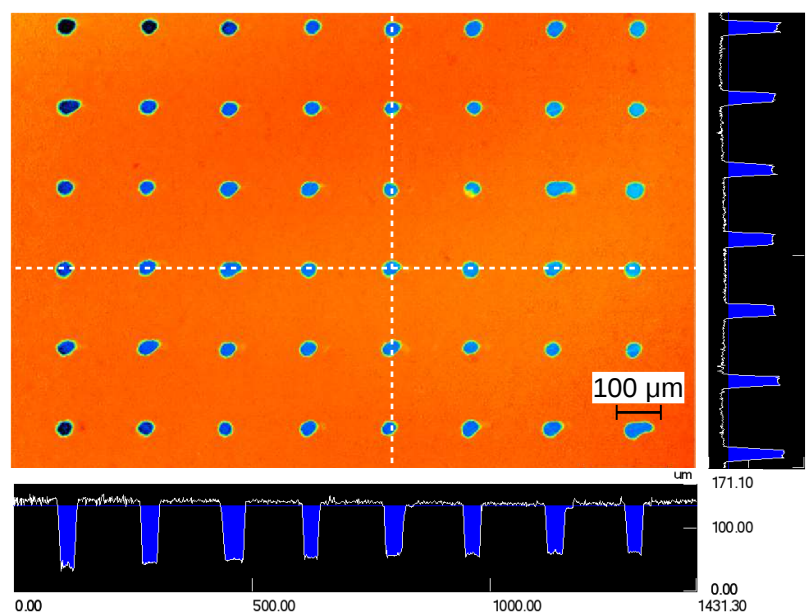

(b)
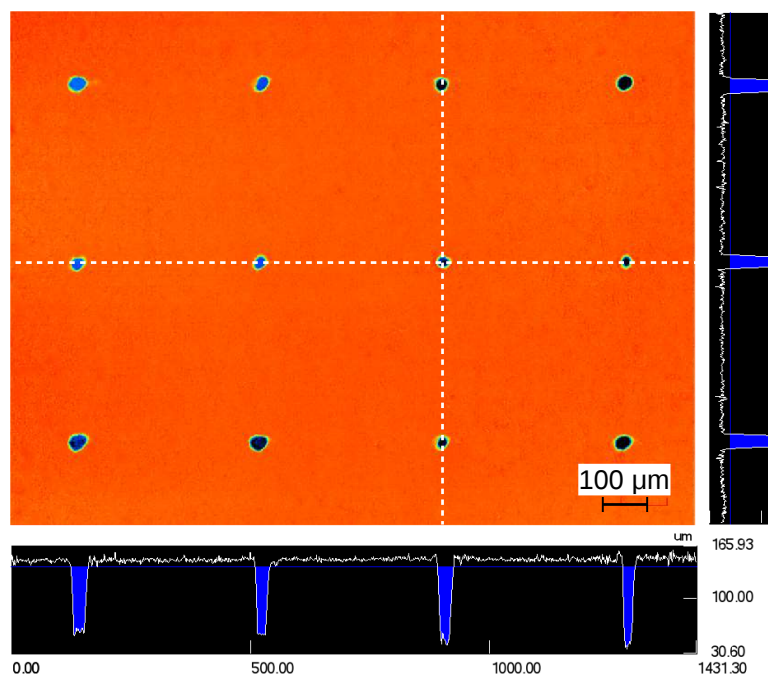

Figure A2. Example confocal laser scanning microscope (CLSM) images of perforated foils summarised in Table 1. (a) 35 perforations per $\mathrm{mm}^{2}$, (b) 7.8 perforations per $\mathrm{mm}^{2}$. Colours represent surface elevation, black bars at the bottom and on the right of each picture show topographic profiles of transects crossing perforations (white dashed lines in main images), with the detection thresholds ( $10 \mu \mathrm{m}$ below surface) marked as blue-filled areas.

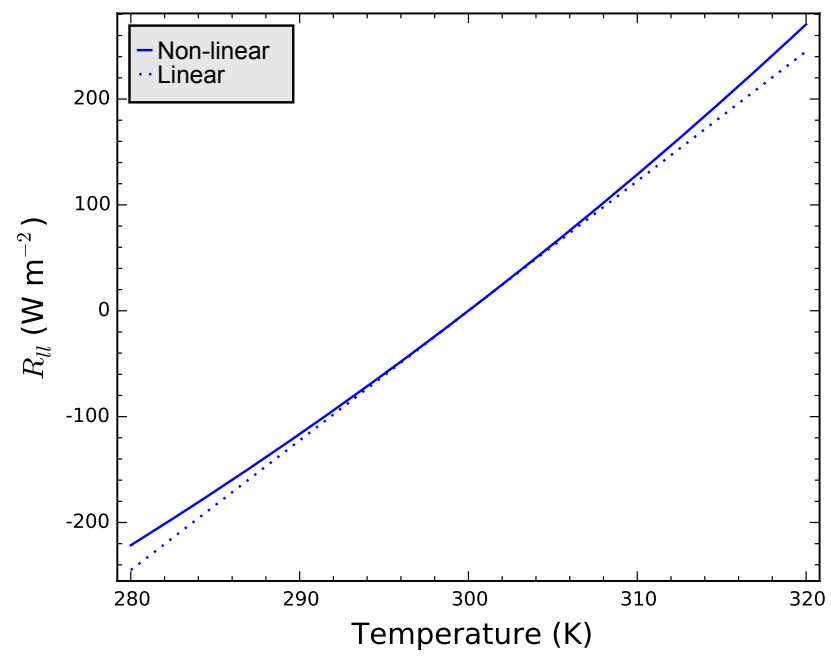

Figure A3. Net long-wave radiation away from leaf as a function of leaf temperature. Solid line represents Eq. (2), while the dotted line represents the linearised function (Eq. 23). Calculations are based on $300 \mathrm{~K}$ air and wall temperature ( $T_{\mathrm{a}}$ and $T_{\mathrm{w}}$, respectively). 


\section{Appendix B: Mathematical derivations}

\section{B1 Boundary layer conductance to water vapour}

The total leaf conductance to water vapour is determined by the boundary layer and stomatal conductances and equal to 1 over the sum of their respective resistances $\left(g_{\mathrm{tw}}=1 /\left(r_{\mathrm{sw}}+\right.\right.$ $\left.r_{\mathrm{bw}}\right)$. The boundary layer conductance for water vapour is equivalent to the mass transfer coefficient for a wet surface (Incropera et al., 2006, Eq. 7.41):

$g_{\mathrm{bw}}=N_{S h_{L}} D_{\mathrm{va}} / L_{1}$,

where $N_{S h_{L}}$ is the dimensionless Sherwood number and $D_{\text {va }}$ is the diffusivity of water vapour in air. If the convection coefficient for heat is known, the one for mass $\left(g_{\mathrm{bw}}\right)$ can readily be calculated from the relation (Incropera et al., 2006, Eq. 6.60)

$g_{\mathrm{bw}}=\frac{a_{\mathrm{s}} h_{\mathrm{c}}}{\rho_{\mathrm{a}} c_{\mathrm{pa}} N_{L e}^{1-n}}$,

where $a_{\mathrm{s}}$ is the fraction of one-sided transpiring surface area in relation to the surface area for sensible heat exchange, $c_{\mathrm{pa}}$ is the constant-pressure heat capacity of air, $n$ is an empirical constant ( $n=1 / 3$ for general purposes) and $N_{L e}$ is the dimensionless Lewis number, defined as (Incropera et al., 2006, Eq. 6.57)

$N_{L e}=\alpha_{\mathrm{a}} / D_{\mathrm{va}}$,

where $\alpha_{\mathrm{a}}$ is the thermal diffusivity of air. The value of $a_{\mathrm{s}}$ was set to 1 for leaves with stomata on one side only, and to 2 for stomata on both sides. Other values could be used for leaves only partly covered by stomata.

\section{B2 Effect of leaf temperature on the leaf-air vapour concentration gradient}

The concentration difference in Eq. (5) is a function of the temperature and the vapour pressure differences between the leaf and the free air. Assuming that water vapour behaves like an ideal gas, we can express its concentration as

$C_{\mathrm{wl}}=\frac{P_{\mathrm{wl}}}{R_{\mathrm{mol}} T_{1}}$,

where $P_{\mathrm{wl}}$ is the vapour pressure inside the leaf, $R_{\mathrm{mol}}$ is the universal gas constant and $T_{1}$ is leaf temperature. A similar relation holds for the vapour concentration in free air, $C_{\text {wa }}=P_{\text {wa }} /\left(R_{\mathrm{mol}} T_{1}\right)$. In this study, the vapour pressure inside the leaf is assumed to be the saturation vapour pressure at leaf temperature, which is computed using the ClausiusClapeyron relation (Hartmann, 1994, Eq. B.3):

$P_{\mathrm{wl}}=611 \exp \left(\frac{\lambda_{E} M_{\mathrm{w}}}{R_{\mathrm{mol}}}\left(\frac{1}{273}-\frac{1}{T_{1}}\right)\right)$, where $\lambda_{E}$ is the latent heat of vaporisation and $M_{\mathrm{W}}$ is the molar mass of water.

Note that the dependence of the leaf-air water concentration difference $\left(C_{\mathrm{wl}}-C_{\mathrm{wa}}\right)$ in Eq. (B4) is very sensitive to leaf temperature. For example, if the leaf temperature increases by $5 \mathrm{~K}$ relative to air temperature, $C_{\mathrm{wl}}-C_{\mathrm{wa}}$ would double, while if leaf temperature decreased by $6 \mathrm{~K}, C_{\mathrm{wl}}-C_{\mathrm{wa}}$ would go to 0 at $70 \%$ relative humidity (Fig. A1).

\section{B3 Concentration or vapour pressure gradient driving transpiration?}

Note that $E_{1, \mathrm{~mol}}$ is commonly expressed as a function of the vapour pressure difference between the free air $\left(P_{\mathrm{wa}}\right)$ and the leaf $\left(P_{\mathrm{wl}}\right)$, in which the conductance $\left(g_{\mathrm{tw}, \mathrm{mol}}\right)$ is expressed in molar units $\left(\mathrm{mol} \mathrm{m}^{-2} \mathrm{~s}^{-1}\right)$ :

$E_{\mathrm{l}, \mathrm{mol}}=g_{\mathrm{tw}, \mathrm{mol}} \frac{P_{\mathrm{wl}}-P_{\mathrm{wa}}}{P_{\mathrm{a}}}$.

For $P_{\mathrm{wl}}=P_{\mathrm{wa}}$, Eq. (5) can still give a flux, whereas Eq. (B6) gives zero flux. This is because the concentrations of vapour in air $\left(\mathrm{mol} \mathrm{m}^{-3}\right)$ can differ due to differences in temperature, even if the partial vapour pressures are the same (see Eq. B4). Therefore, the relation between $g_{\mathrm{tw}}$ and $g_{\mathrm{v}, \mathrm{mol}}$ has an asymptote at the equivalent temperature. It can be obtained by combining Eqs. (5) and (B6) and solving for $g_{\mathrm{tw}, \mathrm{mol}}$ :

$g_{\mathrm{tw}, \mathrm{mol}}=g_{\mathrm{tw}} \frac{P_{\mathrm{a}}\left(P_{\mathrm{wa}} T_{1}-P_{\mathrm{wl}} T_{\mathrm{a}}\right)}{\left.\left(P_{\mathrm{wa}}-P_{\mathrm{wl}}\right) R_{\mathrm{mol}} T_{\mathrm{a}} T_{1}\right)}$.

For $T_{1}=T_{\mathrm{a}}$, the relation simplifies to

$g_{\mathrm{tw}, \mathrm{mol}}=g_{\mathrm{tw}} \frac{P_{\mathrm{a}}}{R_{\mathrm{mol}} T_{\mathrm{a}}}$,

which, for typical values of $P_{\mathrm{a}}$ and $T_{\mathrm{a}}$, amounts to $g_{\mathrm{tw}, \mathrm{mol}} \approx$ $40 \mathrm{~mol} \mathrm{~m}^{-3} g_{\mathrm{tw}}$. For all practical purposes, we found that Eqs. (5) and (B6) with $g_{\mathrm{tw}, \mathrm{mol}}=g_{\mathrm{tw}} \frac{P_{\mathrm{a}}}{R_{\mathrm{mol}} T_{\mathrm{a}}}$ give similar results when plotted as functions of leaf temperature.

\section{B4 Model closure}

Given climatic forcing as $P_{\mathrm{a}}, T_{\mathrm{a}}, R_{\mathrm{s}}, P_{\mathrm{wa}}$ and $v_{\mathrm{w}}$, and leafspecific parameters $a_{\mathrm{s}}, a_{\mathrm{sH}}, L_{1}$ and $g_{\mathrm{sw}}$, we need to compute $C_{\text {wa }}, h_{\mathrm{c}}, g_{\mathrm{bw}}$ and a series of other derived variables, as described below.

The vapour concentration in the free air can be computed from vapour pressure analogously to Eq. (B4):

$C_{\mathrm{wa}}=\frac{P_{\mathrm{wa}}}{R_{\mathrm{mol}} T_{\mathrm{a}}}$.

The heat transfer coefficient $\left(h_{\mathrm{c}}\right)$ for a flat plate can be determined using the non-dimensional Nusselt number $\left(N_{N u_{L}}\right)$ :

$h_{\mathrm{c}}=k_{\mathrm{a}} \frac{N_{N u_{L}}}{L_{1}}$, 
where $k_{\mathrm{a}}$ is the thermal conductivity of the air in the boundary layer and $L_{1}$ is a characteristic length scale of the leaf.

For sufficiently high wind speeds, inertial forces drive the convective heat transport (forced convection) and the relevant dimensionless number is the Reynolds number $\left(N_{R e_{L}}\right)$, which defines the balance between inertial and viscous forces (Incropera et al., 2006, Eq. 6.41):

$N_{R e_{L}}=\frac{v_{\mathrm{w}} L_{1}}{v_{\mathrm{a}}}$,

where $v_{\mathrm{w}}$ is the wind velocity $\left(\mathrm{m} \mathrm{s}^{-1}\right), v_{\mathrm{a}}$ is the kinematic viscosity of the air and $L_{1}$ is taken as the length of the leaf in wind direction.

In the absence of wind, buoyancy forces, driven by the density gradient between the air at the surface of the leaf and the free air dominate convective heat exchange (free or natural convection). The relevant dimensionless number here is the Grashof number $\left(N_{G r_{L}}\right)$, which defines the balance between buoyancy and viscous forces (Incropera et al., 2006, Eqs. 9.3 and 9.65):

$N_{G r_{L}}=\frac{g\left(\frac{\rho_{\mathrm{a}}-\rho_{\mathrm{al}}}{\rho_{\mathrm{al}}}\right) L_{1}^{3}}{v_{\mathrm{a}}^{2}}$,

where $g$ is gravity, while $\rho_{\mathrm{a}}$ and $\rho_{\mathrm{al}}$ are the densities of the gas in the atmosphere and at the leaf surface, respectively.

For $N_{G r_{L}} \ll N_{R e_{L}}^{2}$, forced convection is dominant and free convection can be neglected, whereas for $N_{G r_{L}} \gg N_{R e_{L}}^{2}$ free convection is dominant and forced convection can be neglected (Incropera et al., 2006, p. 565). For simplicity, the analysis is limited to forced conditions, which are satisfied by considering wind speeds greater than $0.5 \mathrm{~m} \mathrm{~s}^{-1}$ for $5 \times 5 \mathrm{~cm}$ leaves.

The average Nusselt number under forced convection was calculated as a function of the average Reynolds number and a critical Reynolds number $\left(N_{R e_{c}}\right)$ that determines the onset of turbulence and depends on the level of turbulence in the free air stream or leaf surface properties (Incropera et al., 2006, p. 412):

$N_{N u_{L}}=\left(0.037 N_{R e_{L}}^{4 / 5}-C_{1}\right) N_{P r}^{1 / 3}$,

with

$C_{1}=0.037 C_{2}^{4 / 5}-0.664 C_{2}^{1 / 2}$

and

$C_{2}=\frac{N_{R e_{L}}+N_{R e_{\mathrm{c}}}-\left|N_{R e_{\mathrm{c}}}-N_{R e_{L}}\right|}{2}$.

Equation (B15) was introduced to make Eq. (B13) valid for all Reynolds numbers, and following considerations explained in our previous work (Schymanski et al., 2013), we chose $N_{R e_{\mathrm{c}}}=3000$ in the present simulations.
In order to simulate steady-state leaf temperatures and the leaf energy balance terms using the above equations, it is necessary to calculate $\rho_{\mathrm{a}}, D_{\mathrm{va}}, \alpha_{\mathrm{a}}, k_{\mathrm{a}}$ and $\nu_{\mathrm{a}}$, while $L_{\mathrm{l}}, R e_{\mathrm{c}}$ and $g_{\mathrm{sv}}$ are input parameters, and $P_{\mathrm{wa}}$ and $v_{\mathrm{w}}$ (vapour pressure and wind speed) are part of the environmental forcing. $D_{\text {va }}$, $\alpha_{\mathrm{a}}, k_{\mathrm{a}}$ and $v_{\mathrm{a}}$ were parameterised as functions of air temperature $\left(T_{\mathrm{a}}\right)$ only, by fitting linear curves to published data (Monteith and Unsworth, 2007, Table A.3):

$D_{\text {va }}=\left(1.49 \times 10^{-7}\right) T_{\mathrm{a}}-1.96 \times 10^{-5}$

$\alpha_{\mathrm{a}}=\left(1.32 \times 10^{-7}\right) T_{\mathrm{a}}-1.73 \times 10^{-5}$

$k_{\mathrm{a}}=\left(6.84 \times 10^{-5}\right) T_{\mathrm{a}}+5.62 \times 10^{-3}$

$v_{\mathrm{a}}=\left(9 \times 10^{-8}\right) T_{\mathrm{a}}-1.13 \times 10^{-5}$.

Assuming that air and water vapour behave like an ideal gas, and that dry air is composed of $79 \% \mathrm{~N}_{2}$ and $21 \% \mathrm{O}_{2}$, we calculated air density as a function of temperature, vapour pressure and the partial pressures of the other two components using the ideal gas law:

$\rho_{\mathrm{a}}=\frac{n_{\mathrm{a}} M_{\mathrm{a}}}{V_{\mathrm{a}}}=M_{\mathrm{a}} \frac{P_{\mathrm{a}}}{R_{\mathrm{mol}} T_{\mathrm{a}}}$,

where $n_{\mathrm{a}}$ is the amount of matter $(\mathrm{mol}), M_{\mathrm{a}}$ is the molar mass $\left(\mathrm{kg} \mathrm{mol}^{-1}\right), P_{\mathrm{a}}$ the pressure, $T_{\mathrm{a}}$ the temperature and $R_{\mathrm{mol}}$ the molar universal gas constant. This equation was used for each component, i.e. water vapour, $\mathrm{N}_{2}$ and $\mathrm{O}_{2}$, where the partial pressures of $\mathrm{N}_{2}$ and $\mathrm{O}_{2}$ are calculated from atmospheric pressure minus vapour pressure, yielding

$\rho_{\mathrm{a}}=\frac{M_{\mathrm{w}} P_{\mathrm{wa}}+M_{\mathrm{N}_{2}} P_{\mathrm{N}_{2}}+M_{\mathrm{O}_{2}} P_{\mathrm{O}_{2}}}{R_{\mathrm{mol}} T_{\mathrm{a}}}$,

where $M_{\mathrm{N}_{2}}$ and $M_{\mathrm{O}_{2}}$ are the molar masses of nitrogen and oxygen, respectively, while $P_{\mathrm{N}_{2}}$ and $P_{\mathrm{O}_{2}}$ are their partial pressures, calculated as

$P_{\mathrm{N}_{2}}=0.79\left(P_{\mathrm{a}}-P_{\mathrm{wa}}\right)$

and

$P_{\mathrm{O}_{2}}=0.21\left(P_{\mathrm{a}}-P_{\mathrm{wa}}\right)$.

\section{B5 Analytical solutions by Penman}

In order to obtain analytical expressions for the different leaf energy balance components, one would need to solve the leaf energy balance equation for leaf temperature first. However, due to the non-linearities of the blackbody radiation and the saturation vapour pressure equations, an analytical solution has not been found yet. Penman (1948) proposed a workaround, which we reproduced below, adapted to our notation and to a wet leaf, while Penman's formulations referred to a wet soil surface. He formulated evaporation from a wet surface as a diffusive process driven by the vapour pressure difference near the wet surface and in the free air:

$E_{\mathrm{w}}=f_{\mathrm{u}}\left(P_{\mathrm{wl}}-P_{\mathrm{wa}}\right)$, 
where $E_{\mathrm{W}}\left(\mathrm{J} \mathrm{s}^{-1} \mathrm{~m}^{-2}\right)$ is the latent heat flux from a wet surface and $f_{\mathrm{u}}$ is commonly referred to as the wind function. Penman then defined the Bowen ratio (Eq. 10 in Penman, 1948) as

$\beta_{\mathrm{B}}=H_{\mathrm{l}} / E_{\mathrm{w}}=\gamma_{\mathrm{v}} \frac{T_{1}-T_{\mathrm{a}}}{P_{\mathrm{wl}}-P_{\mathrm{wa}}}$,

where $H_{1}$ is the sensible heat flux and $\gamma_{\mathrm{v}}$ is the psychrometric constant, referring to the ratio between the transfer coefficients for sensible heat and that for water vapour.

In order to eliminate $T_{1}$, Penman introduced a term for the ratio of the vapour pressure difference between the surface and the saturation vapour pressure at air temperature $\left(P_{\text {was }}\right)$ to the temperature difference between the surface and the air:

$\Delta_{\mathrm{eTa}}=\frac{P_{\mathrm{wl}}-P_{\mathrm{was}}}{T_{1}-T_{\mathrm{a}}}$,

and he proposed to approximate this term by the slope of the saturation vapour pressure curve evaluated at air temperature, which can be obtained by substitution of $T_{\mathrm{a}}$ for $T_{1}$ and differentiation of Eq. (B5) with respect to $T_{\mathrm{a}}$ :

$$
\Delta_{\mathrm{eTa}}=\frac{611 \lambda_{E} M_{\mathrm{w}} \exp \left(\frac{\lambda_{E} M_{\mathrm{w}}}{R_{\mathrm{mol}}}\left(\frac{1}{273}-\frac{1}{T_{\mathrm{a}}}\right)\right)}{R_{\mathrm{mol}} T_{\mathrm{a}}^{2}} .
$$

For further discussion of the meaning of this assumption, please refer to Mallick et al. (2014).

Substitution of Eq. (9) in (B25) (Eq. 15 in Bowen, 1926) yields

$\beta_{\mathrm{B}}=\frac{\gamma_{\mathrm{v}}}{\Delta_{\mathrm{eTa}}} \frac{\left(P_{\mathrm{wl}}-P_{\mathrm{was}}\right)}{\left(P_{\mathrm{wl}}-P_{\mathrm{wa}}\right)}$.

Substituting $E_{\mathrm{w}}$ for $E_{1}$ in the energy balance equation (Eq. 1), inserting $H_{1}=\beta_{\mathrm{B}} E_{\mathrm{W}}$ (Eq. B25) and solving for $E_{\mathrm{w}}$ gives

$E_{\mathrm{w}}=\frac{R_{\mathrm{s}}-R_{\mathrm{ll}}}{\beta_{\mathrm{B}}+1}$.

Substitution of Eq. (B28) into (B29), equating with Eq. (B24) and solving for $P_{\mathrm{wl}}$ gives

$P_{\mathrm{wl}}=\frac{f_{\mathrm{u}}\left(\Delta_{\mathrm{eTa}} P_{\mathrm{wa}}+\gamma_{\mathrm{v}} P_{\mathrm{was}}\right)+\Delta_{\mathrm{eTa}}\left(R_{\mathrm{s}}-R_{\mathrm{ll}}\right)}{f_{\mathrm{u}}\left(\Delta_{\mathrm{eTa}}+\gamma_{\mathrm{v}}\right)}$.

Now, insertion of Eq. (B30) into Eq. (B24) gives the so-called Penman equation:

$E_{\mathrm{w}}=\frac{\Delta_{\mathrm{eTa}}\left(R_{\mathrm{s}}-R_{\mathrm{ll}}\right)+f_{\mathrm{u}} \gamma_{\mathrm{v}}\left(P_{\mathrm{was}}-P_{\mathrm{wa}}\right)}{\Delta_{\mathrm{eTa}}+\gamma_{\mathrm{v}}}$.

Equation (15) is equivalent to Eq. (16) in Penman (1948), but Eq. (17) in Penman (1948), which should be equivalent to Eq. (B30), has $P_{\mathrm{wl}}\left(e_{\mathrm{S}}\right.$ in Penman's notation) on both sides, so it seems to contain an error. In his derivations, Penman expressed $R_{\mathrm{S}}-R_{\mathrm{ll}}$ as "net radiant energy available at surface" and pointed out that the above two equations can be used to estimate $E_{1}$ and $T_{1}$ from air conditions only. This neglects the fact that $R_{11}$ is also a function of the leaf temperature. To estimate surface temperature, Eq. (B30) can be inserted into Eq. (9) and solved for $T_{1}$, yielding

$$
T_{1}=\frac{R_{\mathrm{S}}-R_{11}+f_{\mathrm{u}}\left(\gamma_{\mathrm{v}} T_{\mathrm{a}}+\Delta_{\mathrm{eTa}} T_{\mathrm{a}}+P_{\mathrm{wa}}-P_{\mathrm{was}}\right)}{f_{\mathrm{u}}\left(\gamma_{\mathrm{v}}+\Delta_{\mathrm{eTa}}\right)} .
$$

\section{B5.1 Introduction of stomatal resistance by Penman (1952)}

To account for stomatal resistance to vapour diffusion, Penman (1952) introduced an additional multiplicator $(S)$ in Eq. (B24) (Penman, 1952, Appendix 13):

$E_{1}=f_{\mathrm{u}} S\left(P_{\mathrm{wl}}-P_{\mathrm{wa}}\right)$,

where $S=1$ for a wet surface (leading to Eq. B24) and $S<1$ in the presence of significant stomatal resistance.

In accordance with Eqs. (B24) and (B25), $H_{1}$ can be expressed as (Penman, 1952, Appendix 13)

$H_{1}=\gamma_{\mathrm{v}} f_{\mathrm{u}}\left(T_{1}-T_{\mathrm{a}}\right)$.

Substitution of Penman's simplifying assumption $\left(T_{1}-T_{\mathrm{a}}=\right.$ $\left(P_{\mathrm{wl}}-P_{\mathrm{was}}\right) / \Delta_{\mathrm{eT}}$, Eq. (9) is the first step to eliminating $T_{1}$ :

$H_{\mathrm{l}}=\frac{\gamma_{\mathrm{v}} f_{\mathrm{u}}\left(P_{\mathrm{wl}}-P_{\mathrm{was}}\right)}{\Delta_{\mathrm{eTa}}}$.

A series of algebraic manipulations involving Eqs. (B33), (B35) and (1) and the resulting Eq. (B36) is given in Penman (1952, Appendix 13). When solving Eqs. (B33), (B35) and (1) for $E_{1}, H_{1}$ and $P_{\mathrm{wl}}$, we obtained

$$
\begin{aligned}
& E_{1}=\frac{S \Delta_{\mathrm{eTa}}\left(R_{\mathrm{s}}-R_{11}\right)+S \gamma_{\mathrm{v}} f_{\mathrm{u}}\left(P_{\mathrm{was}}-P_{\mathrm{wa}}\right)}{S \Delta_{\mathrm{eT}}+\gamma_{\mathrm{v}}} \\
& H_{\mathrm{l}}=\frac{\gamma_{\mathrm{v}}\left(R_{\mathrm{s}}-R_{\mathrm{ll}}\right)+S \gamma_{\mathrm{v}} f_{\mathrm{u}}\left(P_{\mathrm{wa}}-P_{\mathrm{was}}\right)}{S \Delta_{\mathrm{eTa}}+\gamma_{\mathrm{v}}} \\
& P_{\mathrm{wl}}=\frac{\left(\Delta_{\mathrm{eTa}} / f_{\mathrm{u}}\right)\left(R_{\mathrm{s}}-R_{11}\right)+\left(S \Delta_{\mathrm{eTa}} P_{\mathrm{wa}}+\gamma_{\mathrm{v}} P_{\mathrm{was}}\right)}{S \Delta_{\mathrm{eTa}}+\gamma_{\mathrm{v}}} .
\end{aligned}
$$

B5.2 Analytical solutions for leaf temperature, $f_{\mathrm{u}}, \gamma_{\mathrm{v}}$ and $S$

Equation (B38) can be inserted into Eq. (9) and solved for leaf temperature to yield

$T_{1}=T_{\mathrm{a}}+\frac{R_{\mathrm{s}}-R_{\mathrm{ll}}-S f_{\mathrm{u}}\left(P_{\mathrm{was}}-P_{\mathrm{wa}}\right)}{f_{\mathrm{u}}\left(S \Delta_{\mathrm{eT}}+\gamma_{\mathrm{v}}\right)}$.

Penman (1952) proposed to obtain values of $f_{\mathrm{u}}$ and $S$ for a plant canopy empirically and described ways to do this. However, for a single leaf, $f_{\mathrm{u}}$ and $S$ could also be obtained analytically from our detailed mass and heat transfer model.

Comparison of Eq. (B33) with (B6) (after substituting Eq. 4) reveals that $S$ is equivalent to

$S=\frac{M_{\mathrm{w}} g_{\mathrm{tw}, \mathrm{mol}} \lambda_{E}}{P_{\mathrm{a}} f_{\mathrm{u}}}$, 
where $f_{\mathrm{u}}$ was defined by Penman (1948) as the transfer coefficient for wet surface evaporation, i.e. a function of the boundary layer conductance only.

To find a solution for $f_{\mathrm{u}}$, we first formulate $E_{\mathrm{w}}$ as transpiration from a leaf where $g_{\mathrm{tw}}=g_{\mathrm{bw}}$, using Eqs. (4), (B6) and (B8):

$E_{\mathrm{w}}=\frac{\lambda_{E} M_{\mathrm{w}} g_{\mathrm{bw}}}{R_{\mathrm{mol}} T_{\mathrm{a}}}\left(P_{\mathrm{wl}}-P_{\mathrm{wa}}\right)$.

Comparison of Eq. (B41) with (B24) gives $f_{\mathrm{u}}$ as a function of $g_{\mathrm{bw}}$ :

$f_{\mathrm{u}}=g_{\mathrm{bw}} \frac{\lambda_{E} M_{\mathrm{w}}}{R_{\mathrm{mol}} T_{\mathrm{a}}}$.

Comparison of Eq. (B34) and (3) reveals that

$\gamma_{\mathrm{v}}=\frac{a_{\mathrm{sh}} h_{\mathrm{c}}}{f_{\mathrm{u}}}$,

and insertion of Eqs. (B42) and (B2) give $\gamma_{\mathrm{v}}$ as a function of $a_{\text {sh }}$ and $a_{\mathrm{s}}$ :

$\gamma_{\mathrm{v}}=a_{\mathrm{sh}} / a_{\mathrm{s}} \frac{N_{L e^{\frac{2}{3}}} R_{\mathrm{mol}} T_{\mathrm{a}} \rho_{\mathrm{a}} c_{\mathrm{pa}}}{\lambda_{E} M_{\mathrm{w}}}$.

Now, we can insert Eqs. (B42), (B8) and (6) into (B40) to obtain $S$ as a function of $g_{\text {sw }}$ and $g_{\text {bw }}$ :

$S=\frac{g_{\mathrm{sw}}}{g_{\mathrm{bw}}+g_{\mathrm{sw}}}$.

The above equation illustrates that $S$ is not just a function of stomatal conductance, but also the leaf boundary layer conductance, explaining why Penman (1952) found that $S$ depends on wind speed.

\section{B6 Psychrometric constant in the Penman-Monteith equation}

Monteith and Unsworth (2013) provide a definition of $\gamma_{\mathrm{v}}$ as

$\gamma_{\mathrm{v}}=\frac{c_{\mathrm{pa}} P_{\mathrm{a}}}{\lambda_{E} \epsilon}$,

where $\epsilon$ is the ratio of molecular weights of water vapour and air (given by Monteith and Unsworth, 2013 as 0.622). The molar mass of air is $M_{\mathrm{a}}=\rho_{\mathrm{a}} V_{\mathrm{a}} / n_{\mathrm{a}}$, while according to the ideal gas law, $V_{\mathrm{a}} / n_{\mathrm{a}}=R_{\mathrm{mol}} T_{\mathrm{a}} / P_{\mathrm{a}}$, which yields for $\epsilon=$ $M_{\mathrm{w}} / M_{\mathrm{a}}$ :

$\epsilon=\frac{M_{\mathrm{w}} P_{\mathrm{a}}}{R_{\mathrm{mol}} T_{\mathrm{a}} \rho_{\mathrm{a}}}$.

Inserting Eqs. (B21), (B22) and (B23) into the above, $T_{\mathrm{a}}$ cancels out, and at standard atmospheric pressure of $101325 \mathrm{~Pa}$, we obtain values for $\epsilon$ between 0.624 and 0.631 for vapour pressure ranging from 0 to $3000 \mathrm{~Pa}$, compared to the value of 0.622 mentioned by Monteith and Unsworth (2013).

\section{B7 Meaning of resistances in PM equation}

As opposed to the formulations in Sect. 2.1, where sensible and latent heat transfer coefficients $\left(h_{\mathrm{c}}\right.$ and $g_{\mathrm{tw}}$, respectively) translate leaf-air differences in temperature or vapour concentration to fluxes, resistances in the PM equation are defined in the context of the following two equations (Monteith and Unsworth, 2013, Eqs. 13.16 and 13.20):

$E_{1}=\frac{a_{\mathrm{s}} \lambda_{E} \rho_{\mathrm{a}} \epsilon}{P_{\mathrm{a}}\left(r_{\mathrm{v}}+r_{\mathrm{s}}\right)}\left(P_{\mathrm{wl}}-P_{\mathrm{wa}}\right)$

and

$H_{1}=\frac{a_{\mathrm{sh}} \rho_{\mathrm{a}} c_{\mathrm{pa}}}{r_{\mathrm{a}}}\left(T_{1}-T_{\mathrm{a}}\right)$,

where $r_{\mathrm{v}}$ and $r_{\mathrm{S}}$ are the one-sided leaf boundary layer and stomatal resistances to water vapour, respectively, and $r_{\mathrm{a}}$ is the one-sided leaf boundary layer resistance to sensible heat transfer. Note that we introduced $a_{\mathrm{s}}, a_{\mathrm{sh}}$ and $r_{\mathrm{s}}$ in Eqs. (B48) and (B49) based on the description on p. 231 in Monteith and Unsworth (2013), where the authors also assumed that $r_{\mathrm{v}} \approx r_{\mathrm{a}}{ }^{1}$

Comparison of Eq. (B48) (after substitution of Eq. B47) with our fundamental diffusion equation (Eq. 5, after substitution of Eqs. B4 and B9 and insertion into Eq. 4) reveals that under isothermal conditions $\left(T_{1}=T_{\mathrm{a}}\right)$

$r_{\mathrm{v}}=a_{\mathrm{s}} / g_{\mathrm{bw}}$

while comparison of Eq. (B49) with Eq. (3) reveals that

$r_{\mathrm{a}}=\frac{\rho_{\mathrm{a}} c_{\mathrm{pa}}}{h_{\mathrm{c}}}$.

\section{B8 Comparison of our general analytical solution with original Penman and Penman-Monteith equations}

From the general form (Eq. 10), we can recover most of the above analytical solutions by appropriate substitutions for $c_{E}$ and $c_{H}$, but closer inspection of the necessary substitutions reveals some inconsistencies.

The Penman equation for a wet surface (Eq. 15) can be recovered by substituting $c_{E}=f_{\mathrm{u}}$ and $c_{H}=\gamma_{\mathrm{v}} f_{\mathrm{u}}$ into Eq. (10) (Fig. 3a), while additional substitution of Eq. (17) leads to recovery of Eq. (16), the Penman equation as reformulated by Monteith (1965). The formulation for leaf transpiration derived by Penman (1952) (Eq. B36) is obtained by substituting $c_{E}=S f_{\mathrm{u}}$ (deduced from Eq. B33) and $c_{H}=\gamma_{\mathrm{v}} f_{\mathrm{u}}$ (from Eq. B34). These substitutions are consistent with the formulations of latent and sensible heat flux given in Eqs. (B34) and (B24) or (B33), as long as $f_{\mathrm{u}}$ and $r_{\mathrm{a}}$ refer to the total resistances of a leaf to latent and sensible heat flux, respectively, as Eq. (17) in conjunction with $c_{H}=\gamma_{\mathrm{v}} f_{\mathrm{u}}$ implies that

$c_{H}=\left(\rho_{\mathrm{a}} c_{\mathrm{pa}}\right) / r_{\mathrm{a}}$.

\footnotetext{
${ }^{1}$ Division of Eq. (B51) by (B50) and substitution of Eqs. (B2), (B3), (B17) and (B16) reveals that $r_{\mathrm{a}} / r_{\mathrm{v}}=N_{L e}^{-2 / 3}=1.082$.
} 
Similarly, the Penman-Monteith equation (Eq. 19 with $\gamma_{\mathrm{v}}$ defined in Eq. B46) could be recovered by substituting $c_{E}=\epsilon \lambda_{E} \rho_{\mathrm{a}} /\left(P_{\mathrm{a}}\left(r_{\mathrm{s}}+r_{\mathrm{v}}\right)\right)$ and $c_{H}=c_{\mathrm{pa}} \rho_{\mathrm{a}} / r_{\mathrm{a}}$, with subsequent substitution of $r_{\mathrm{v}}=r_{\mathrm{a}}$. Note, however, that these substitutions are not consistent with Eqs. (B48) and (B49), as the factors $a_{\mathrm{s}}$ and $a_{\mathrm{sh}}$ (referring to the number of leaf faces exchanging latent and sensible heat flux, respectively) are missing (Fig. 3b cf. 3c). This is because the PM equation was derived with a soil surface in mind, which exchanges latent and sensible heat only on one side, and hence is not appropriate for a leaf. To alleviate this constraint, one could define $r_{\mathrm{a}}$ and $r_{\mathrm{s}}$ as total (two-sided) leaf resistances, but in this case, the simplification $r_{\mathrm{v}} \approx r_{\mathrm{a}}$ is not valid for hypostomatous leaves, as $r_{\mathrm{a}}$ would then be only half of $r_{\mathrm{v}}$. This is illustrated in Fig. 3c, where sensible heat flux is released from both sides of the leaf, while latent heat flux is only released from the abaxial side, implying that $a_{\mathrm{sh}}=2$ and $a_{\mathrm{s}}=1$.

Monteith and Unsworth (2013) acknowledged that a hypostomatous leaf could exchange sensible heat on two sides, but latent heat on one side only and introduced the parameter $n_{\mathrm{MU}}=a_{\mathrm{sh}} / a_{\mathrm{s}}$ to account for this (Eq. 21). Using our general equation, it should be possible to reproduce the MU equation (Eq. 21) by substituting $c_{E}=a_{\mathrm{s}} \in \lambda_{E} \rho_{\mathrm{a}} /\left(P_{\mathrm{a}}\left(r_{\mathrm{s}}+r_{\mathrm{v}}\right)\right)$ (deduced from Eq. B48) and $c_{H}=a_{\mathrm{sh}} c_{\mathrm{pa}} \rho_{\mathrm{a}} / r_{\mathrm{a}}$ (deduced from Eq. B49) into Eq. (10). However, the result of this substitution, as presented in Eq. (B53), is not the same as Eq. (21) after substitution of Eq. (B46) and $n_{\mathrm{MU}}=a_{\mathrm{sh}} / a_{\mathrm{s}}$, which would result in Eq. (B54):

$E_{1}=\frac{a_{\mathrm{s}} \in \lambda_{E}\left(\Delta_{\mathrm{eTa}} r_{\mathrm{a}}\left(R_{\mathrm{s}}-R_{\mathrm{ll}}\right)+a_{\mathrm{sh}} c_{\mathrm{pa}} \rho_{\mathrm{a}}\left(P_{\mathrm{was}}-P_{\mathrm{wa}}\right)\right)}{P_{\mathrm{a}} a_{\mathrm{sh}} c_{\mathrm{pa}}\left(r_{\mathrm{s}}+r_{\mathrm{a}}\right)+\Delta_{\mathrm{eTa}} a_{\mathrm{s}} \in \lambda_{E}}$

vs.

$E_{1}=\frac{a_{\mathrm{s}} \in \lambda_{E}\left(\Delta_{\mathrm{eTa}} r_{\mathrm{a}}\left(R_{\mathrm{s}}-R_{\mathrm{ll}}\right)+c_{\mathrm{pa}} \rho_{\mathrm{a}}\left(P_{\mathrm{was}}-P_{\mathrm{wa}}\right)\right)}{P_{\mathrm{a}} a_{\mathrm{sh}} c_{\mathrm{pa}}\left(r_{\mathrm{s}}+r_{\mathrm{a}}\right)+\Delta_{\mathrm{eTa}} a_{\mathrm{s}} \in \lambda_{E}}$.

Note the missing $a_{\mathrm{sh}}$ in the nominator of Eq. (B54), as pointed out in the main text.

\section{B9 Surface temperature dependence of net radiation}

In the main text, Eq. (2) was linearised by taking its derivative with respect to $T_{1}$, defining this derivative as the slope of a linear function of temperature with an intercept chosen to make this function intersect with Eq. (2) at $T_{1}=T_{\mathrm{a}}$. The result is given in Eq. (23) and plotted in Fig. (A3).

\section{B10 Calculation of stomatal conductance from pore dimensions}

At least three confocal laser scanning images of each perforated foil were analysed and average pore area $\left(A_{\mathrm{p}}, \mathrm{m}^{2}\right)$, pore radius $\left(r_{\mathrm{p}}, \mathrm{m}\right)$, number of pores per surface area $\left(n_{\mathrm{p}}\right.$, $\left.\mathrm{m}^{-2}\right)$ and average distance to nearest neighbour $\left(s_{\mathrm{p}}, \mathrm{m}\right)$ was computed for each image. The resulting stomatal conductance was computed following the derivations presented by Lehmann and Or (2015), assuming that the stomatal conductance results from two resistances in a series: the throat resistance $\left(r_{\mathrm{sp}}\right)$, dependent on the areas of the pores and the thickness of the perforated foil $\left(d_{\mathrm{p}}\right)$, and the vapour shell resistance $\left(r_{\mathrm{vs}}\right)$, dependent on the size and spacing of the stomata, which can be understood as the resistance related to distribution of the point-source water vapour over the entire one-sided leaf boundary layer. We hereby neglect any internal resistance (termed "end correction" by Lehmann and Or, 2015), as we assume that the wet filter paper has direct contact with the perforated foil. The throat resistance was computed (Eq. 1 in Lehmann and Or, 2015) as

$r_{\mathrm{sp}}=\frac{d_{\mathrm{p}}}{A_{\mathrm{p}} k_{\mathrm{dv}} n_{\mathrm{p}}}$,

where $k_{\mathrm{dv}}$ is the ratio of the vapour diffusion coefficient and the molar volume of air $\left(D_{\mathrm{va}} / V_{\mathrm{m}}\right)$, and $A_{\mathrm{p}}=\pi r_{\mathrm{p}}^{2}$. For the vapour shell resistance, we use the formulation originally proposed by Bange (1953):

$r_{\mathrm{vs}}=\left(\frac{1}{4 r_{\mathrm{p}}}-\frac{1}{\pi s_{\mathrm{p}}}\right) \frac{1}{k_{\mathrm{dv}} n_{\mathrm{p}}}$,

where $s_{\mathrm{p}}(\mathrm{m})$ is the spacing between stomata, inferred from the images as $s_{\mathrm{p}}=1 / \sqrt{n_{\mathrm{p}}}$. Stomatal conductance $\left(g_{\mathrm{sw}}\right)$ for each image was then calculated following Eq. (B8), i.e. $g_{\mathrm{sw}}=g_{\mathrm{sw}, \mathrm{mol}} R_{\mathrm{mol}} T_{\mathrm{a}} / P_{\mathrm{a}}$, after substituting $g_{\mathrm{sw}, \mathrm{mol}}=$ $1 /\left(r_{\mathrm{sp}}+r_{\mathrm{vs}}\right)$. 
Author contributions. Stanislaus J. Schymanski performed the mathematical derivations, designed and carried out the experiments and wrote the paper. Dani Or was involved in the design of the experimental set-up, interpretation of the results and writing the paper.

Competing interests. The authors declare that they have no conflict of interest.

Acknowledgements. The authors are very grateful to Dani Breitenstein for his assistance in designing and constructing the wind tunnel, to Stefan Meier and Joni Dehaspe for assistance in constructing artificial leaves and to Hans Wunderli for assistance in the lab. We also wish to acknowledge technical advice by Roland Kuenzli (DMP AG, Fehraltorf, Switzerland), laser perforation services by Ralph Beglinger (Lasergraph AG, Würenlingen, Switzerland), Robert Voss (ETH Zurich, Switzerland) and Rolf Brönnimann (EMPA, Zurich, Switzerland), helpful feedback from Tim Reichenau and Claire Zimmermann (Univ. Köln, Germany) and constructive reviewer comments by Stefan Dekker and an anonymous reviewer. The project benefited from funding by the Swiss National Science Foundation (project 200021 135077).

Edited by: P. Gentine

Reviewed by: S. C. Dekker and one anonymous referee

\section{References}

Allen, R.: A Penman for All Seasons, J. Irrig. Drain. Eng.-ASCE, 112, 348-368, doi:10.1061/(ASCE)07339437(1986)112:4(348), 1986.

Bange, G. G. J.: On the quantitative explanation of stomatal transpiration, Acta Bot. Neerl., 2, 255-296, 1953.

Bowen, I. S.: The Ratio of Heat Losses by Conduction and by Evaporation from any Water Surface, Phys. Rev., 27, 779-787, doi:10.1103/PhysRev.27.779, 1926.

Dolman, A. J., Miralles, D. G., and de Jeu, R. A.: Fifty years since Monteith's 1965 seminal paper: the emergence of global ecohydrology: the emergence global ecohydrology, Ecohydrology, 7, 897-902, doi:10.1002/eco.1505, 2014.

Hartmann, D. L.: Global physical climatology, Academic Press, 1994.

Incropera, F. P., DeWitt, D. P., Bergman, T. L., and Lavine, A. S.: Fundamentals of Heat and Mass Transfer, John Wiley \& Sons, 6th Edn., 2006.

Jarvis, A. J. and McNaughton, K. G.: Stomatal Control of Transpiration: Scaling Up from Leaf to Region, Adv. Ecol. Res., 15, $1-49,1986$.

Langensiepen, M., Fuchs, M., Bergamaschi, H., Moreshet, S., Cohen, Y., Wolff, P., Jutzi, S. C., Cohen, S., Rosa, L. M. G., Li, Y., and Fricke, T.: Quantifying the uncertainties of transpiration calculations with the Penman-Monteith equation under different climate and optimum water supply conditions, Agr. Forest Meteorol., 149, 1063-1072, doi:10.1016/j.agrformet.2009.01.001, 2009.
Lehmann, P. and Or, D.: Effects of stomata clustering on leaf gas exchange, New Phytol., 207, 1015-1025, doi:10.1111/nph.13442, 2015.

Leuning, R., Grace, J., Monteith, J. L., Milford, J. R., Unsworth, M. H., and Fowler, D.: Leaf Energy Balances: Developments and Applications [and Discussion], Philos. T. R. Soc. B, 324, 191206, doi:10.1098/rstb.1989.0044, 1989.

Lhomme, J. P., Montes, C., Jacob, F., and Prévot, L.: Evaporation from Heterogeneous and Sparse Canopies: On the Formulations Related to Multi-Source Representations, Bound.-Lay. Meteorol., 144, 243-262, doi:10.1007/s10546-012-9713-x, 2012.

Mallick, K., Jarvis, A., Fisher, J. B., Tu, K. P., Boegh, E., and Niyogi, D.: Latent Heat Flux and Canopy Conductance Based on Penman-Monteith, Priestley-Taylor Equation, and Bouchet's Complementary Hypothesis, J. Hydrometeorol., 14, 419-442, doi:10.1175/JHM-D-12-0117.1, 2013.

Mallick, K., Jarvis, A. J., Boegh, E., Fisher, J. B., Drewry, D. T., Tu, K. P., Hook, S. J., Hulley, G., Ardö, J., Beringer, J., Arain, A., and Niyogi, D.: A Surface Temperature Initiated Closure (STIC) for surface energy balance fluxes, Remote Sens. Environ., 141, 243-261, doi:10.1016/j.rse.2013.10.022, 2014.

Mallick, K., Trebs, I., Boegh, E., Giustarini, L., Schlerf, M., Drewry, D. T., Hoffmann, L., von Randow, C., Kruijt, B., Araùjo, A., Saleska, S., Ehleringer, J. R., Domingues, T. F., Ometto, J. P. H. B., Nobre, A. D., de Moraes, O. L. L., Hayek, M., Munger, J. W., and Wofsy, S. C.: Canopy-scale biophysical controls of transpiration and evaporation in the Amazon Basin, Hydrol. Earth Syst. Sci., 20, 4237-4264, doi:10.5194/hess-20-4237-2016, 2016.

McArthur, A. J.: An accurate solution to the Penman equation, Agr. Forest Meteorol., 51, 87-92, doi:10.1016/0168-1923(90)900436, 1990.

Milly, P. C. D.: A refinement of the combination equations for evaporation, Surv. Geophys., 12, 145-154, doi:10.1007/BF01903416, 1991.

Monteith, J. and Unsworth, M.: Principles of Environmental Physics, Academic Press, Oxford, UK, 3rd Edn., 2007.

Monteith, J. L.: Evaporation and environment, Sym. Soc. Exp. Biol., 19, 205-234, doi:10.1002/qj.49710745102, 1965.

Monteith, J. L. and Unsworth, M. H.: Principles of environmental physics: plants, animals, and the atmosphere, 4th Edn., Elsevier/Academic Press, Amsterdam, Boston, 2013.

Overgaard, J., Rosbjerg, D., and Butts, M. B.: Land-surface modelling in hydrological perspective - a review, Biogeosciences, 3, 229-241, doi:10.5194/bg-3-229-2006, 2006.

Parlange, J.-Y., Waggoner, P. E., and Heichel, G. H.: Boundary Layer Resistance and Temperature Distribution on Still and Flapping Leaves, Plant Physiol., 48, 437-442, 1971.

Paw U, K. T. and Gao, W.: Applications of solutions to non-linear energy budget equations, Agr. Forest Meteorol., 43, 121-145, doi:10.1016/0168-1923(88)90087-1, 1988.

Penman, H. L.: Natural Evaporation from Open Water, Bare Soil and Grass, P. R. Soc. A, 193, 120-145, doi:10.1098/rspa.1948.0037, 1948.

Penman, H. L.: The physical bases of irrigation control, International Horticultural Congress, 2, 913-924, 1952.

Raupach, M. R.: Vegetation-atmosphere interaction and surface conductance at leaf, canopy and regional scales, Agr. Forest Meteorol., 73, 151-179, doi:10.1016/0168-1923(94)05071-D, 1995. 
Raupach, M. R. and Finnigan, J. J.: "Single-layer models of evaporation from plant canopies are incorrect but useful, whereas multilayer models are correct but useless": Discuss, Funct. Plant Biol., 15, 705-716, doi:10.1071/PP9880705, 1988.

Schymanski, S.: Data and code to reproduce computational results and plots, doi:10.5281/zenodo.241259, 2017.

Schymanski, S. J. and Or, D.: Wind effects on leaf transpiration challenge the concept of "potential evaporation", Proc. IAHS, 371, 99-107, doi:10.5194/piahs-371-99-2015, 2015.

Schymanski, S. J. and Or, D.: Wind increases leaf water use efficiency, Plant Cell Environ., 39, 1448-1459, doi:10.1111/pce.12700, 2016.

Schymanski, S. J., Or, D., and Zwieniecki, M.: Stomatal Control and Leaf Thermal and Hydraulic Capacitances under Rapid Environmental Fluctuations, PLoS ONE, 8, e54231, doi:10.1371/journal.pone.0054231, 2013.

Schymanski, S. J., Breitenstein, D., and Or, D.: Technical note: An experimental setup to measure latent and sensible heat fluxes from (artificial) plant leaves, Hydrol. Earth Syst. Sci. Discuss., doi:10.5194/hess-2016-643, in review, 2017.
Schymanski, S. J., Breitenstein, D., and Or, D.: Technical note: An experimental setup to measure latent and sensible heat fluxes from (artificial) plant leaves, Hydrol. Earth Syst. Sci. Discuss., doi:10.5194/hess-2016-643, in review, 2017.

Tanner, C. B. and Fuchs, M.: Evaporation from unsaturated surfaces: A generalized combination method, J. Geophys. Res., 73, 1299-1304, doi:10.1029/JB073i004p01299, 1968.

Verhoef, A. and Allen, S. J.: A SVAT scheme describing energy and $\mathrm{CO}_{2}$ fluxes for multi-component vegetation: calibration and test for a Sahelian savannah, Ecol. Model., 127, 245-267, doi:10.1016/S0304-3800(99)00213-6, 2000.

Widmoser, P.: A discussion on and alternative to the PenmanMonteith equation, Agr. Water Manage., 96, 711-721, doi:10.1016/j.agwat.2008.10.003, 2009. 